\title{
PREDICTIVE CONTROL OF A MIXER-SETTLER EXTRACTOR SEPARATING THE RARE-EARTHS
}

\author{
$\mathrm{Ph}$.D. Thesis submitted to lowa State University, \\ February, 1973
}

R. C. Seemann

\author{
Ames Laboratory, USAEC \\ lowa State University
} Ames, lowa 50010 This report was prepared as an account of work
sponsured Uy the United States Government. Neither
the United States nor the United States Atomic Energy
Commission, nor any of their employees, nor any of
their contractors, subcontractors, or their employees,
makes any warranty, express or implied, or assumes any
legal liability or responsibility for the accuracy, com-
pleteness or usefulness of any information, apparatus,
product or process disclosed, or represents that its use
would not infringe privately owned rights.

Date of Manuscript: February, 1973

\section{MASTER}

PREPARED FOR THE U. S. ATOMIC ENERGY COMMISSION DIVISION OF RESEARCH UNDER CONTRACT NO. W-7405-eng-82 


\section{DISCLAIMER}

This report was prepared as an account of work sponsored by an agency of the United States Government. Neither the United States Government nor any agency Thereof, nor any of their employees, makes any warranty, express or implied, or assumes any legal liability or responsibility for the accuracy, completeness, or usefulness of any information, apparatus, product, or process disclosed, or represents that its use would not infringe privately owned rights. Reference herein to any specific commercial product, process, or service by trade name, trademark, manufacturer, or otherwise does not necessarily constitute or imply its endorsement, recommendation, or favoring by the United States Government or any agency thereof. The views and opinions of authors expressed herein do not necessarily state or reflect those of the United States Government or any agency thereof. 


\section{DISCLAIMER}

Portions of this document may be illegible in electronic image products. Images are produced from the best available original document. 
NOTICE

This report was prepared as an account of work sponsored by the United States Government. Neither the United States nor the United States Atomic Energy Commission, nor any of their employees, nor any of their contractors, subcontractors, or their employees, makes any warranty, express or implied, or assumes any legal liability or responsibility for the accuracy, completeness or usefulness of any information, apparatus, product or process disclosed, or represents that its use would not infringe privately owned rights.

Available from: National Technical Information Service Department $A$

Springfield, VA 22151

Price: Microflche $\$ 0.95$ 

Predictive control of a mixer-settler extractor separating the rare-earths

by

Richard Charles Seemann

A Dissertation submitted to the Graduate Faculty in Partial Fulfillment of

The Requirements for the Degree of DOCTOR OF PHILOSOPHY

Major: Chemical Engineering

Approved :

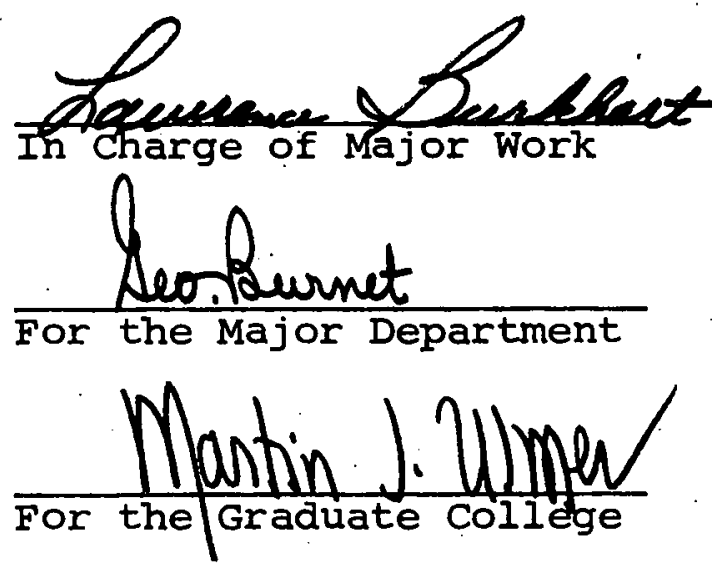

Iowa 3tate. University

Ames, Iowa 
TABLE OF CONTENTS

NOMENCLATURE

ABSTRACT

INTRODUCTION

\section{Page}

Solvent Extraction

Extractor Control.

3

Rare-Earths 4

Objectives . 6

REVIEW OF RELATED WORK

Extractor Simulation 7

Predictive Control 9

$\begin{array}{ll}\text { THEORY } & 13\end{array}$

Extractor Simulation 13

Predictive Control $\quad 21$

Steady state gain 23

Dynamic compensation 24

$\begin{array}{ll}\text { Calculational Procedure } & 27\end{array}$

DESCRIPTION OF RARE-EARTH SYSTEM, EXTRACTOR, AND EXTRACTOR CHARACTERISTICS

The Rare-Earth System , 31

$\begin{array}{ll}\text { The Extractor } & 32\end{array}$

Extractor Characteristics 35

CONTROL STRATEGY - $\quad 39$ 
RESULTS AND DISCUSSION $\quad$ * * $\quad 44$

Extractor Simulation $\quad 44$

Solvent Flow Rate Predictive control 48

Other Predictive Control Variables 70.

CONCLUSIONS $\quad \cdots \quad 72$

IITERATURE CITED $\quad \cdots 4$

$\begin{array}{ll}\text { ACKNOWLEDGMENTS } & 77\end{array}$ 
(1)

\section{NOMENCLATURE}

A Aqueous phase hydrochloric acid concentration, moles/liter

C $\quad$ Constant vector, Equation 7

$\supseteqq \quad$ Coefficient matrix, Equation 7

E Solvent flow rate into extractor, liters/min

$E_{j} \quad$ Solvent flow rate from stage $j$, liters $/ \mathrm{min}$

$E(t)$ Solvent flow rate set by controller, Equation 19, liters $/ \mathrm{min}$

$E_{D}(t)$. Dynamic compensation term of predictive control model, Equation 17

$\mathrm{E}_{\mathrm{p}} \quad$ Steady state gain term of predictive control model, Equation 14, liters/min.

$E_{p}\left(t ; E_{s}\right)$ Predicted value of solvent flow rate, Equation 17, Iiters/min

$E_{S} \quad$ Solvent flow rate into extractor, Equation 17, liters/min

$E_{\text {sp }}$ Desired set point value for solvent flow rate, liters/min

F Feed flow rate, liters/min

$\mathrm{H}$ Aqueous phase holdup, liters

h Organic phase holdup, liters

I Measured input variable, Equation 15

K Distribution coefficient, Equation 5

o Output variable, Equation 15

Re Samarium recovery

$R_{p} \quad$ Raffinate purity

S Aqueous phase flow rate, liters/min 
$t$

$\mathbf{x}$.

$x_{p}$

$\mathrm{x}_{\mathrm{T}}$

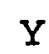

$\mathrm{Y}_{\mathrm{T}}$

Greek

$\alpha$

$\beta$

$\beta_{i, j}$

$\varepsilon$

$\tau$

$\delta t$

Subscripts and Superscripts

i Rare-earth component

j Stage number

f

Time, min

Total stage volume, liters liter

Extract purity moles/liter liter moles/liter

Flow ratio (=S/E)

Flow ratio $(=E /(S+F))$

Separation factor

Time constant

Feed stage.
Aqueous phase rare-earth concentration, moles/

Total aqueous phase rare-earth concentration,

Organic phase rare-earth concentration, moles/

Total organic phase rare-earth concentration,

Deviation of output variable from its set point

Numerical integration time increment 
viii

\author{
Predictive control of a mixer-settler extractor \\ separating the rare-earths \\ Richard Charles Seemann
}

Under the supervision of Lawrence Burkhart From the Department of Chemical Engineering Iowa State University

This study was concerned with the determination of a predictive control model for a mixer-settler extractor using the dynamic simulation of the extractor. The simulation incorporated the actual equilibrium relationships for the rareearth system cerium, neodymium, and samarium and it accounted for transport delays in an extractor by including first order time lags for flow rate changes. The simulation was used both for determining steady state operating conditions and for obtaining dynamic responses of the extractor as well as using it as a stand-in for the real extractor in the predictive control studies.

In the predictive control work the control variable was solvent flow rate and the output variables that were controlled were samarium purity in the extract and samarium recovery. For an upset in a measured input variable one 
output variable would decrease and the other increase. Because of these output variable characteristics and because of the restrictions placed on the output variables it was possible to control the two output variables with one control variable: The measured input variables whose upsets were controlled were the feed concentration of samarium and the feed flow rate.

The predictive control model consisted of three distinct terms. The first was a steady state gain term which gave the final steady state value of the control variable for a measured input variable change. This gain term was represented by a linear regression equation which was determined using data from a steady state analysis of the extractor. The dynamic compensation term was included in those cases where transients in the output variable resulting from using only a steady state gain term were larger than desired. This compensation term was obtained from a combination of the dynamic responses to control and measured input variable changes. The final term was a feedback trimmer which was used to eliminate any final offset in the output variable which might result after an upset because of inaccuracies in the linear steady state gain term.

The feed to the extractor was $\mathrm{CeCl}_{3}-\mathrm{NaCl}_{3}-\mathrm{SmCl}_{3}-\mathrm{HCl}-\mathrm{H}_{2} \mathrm{O}$. The solvent was di-(2-ethylhexyl) phosphoric acid, D2EHPA, in Amsco Odorless Mineral Spirits. The extraction separated 
samarium into the extract stream and cerium and neodymium into the raffinate stream. 


\section{INTRODUCTION}

\section{Solvent Extraction}

Solvent extraction is a separation process in which two immiscible phases come in contact with one phase selectively removing differing amounts of each of the extractable materials, or solutes, from the other phase. A common example of such a process is the contacting of an organic solvent phase with an aqueous phase containing several solutes. The measure of the phase selectivity for a particular solute is the distribution coefficient. It is defined as the ratio of the solute's organic phase concentration to the solute's aqueous phase concentration. The ease with which two solutes can be separated is measured by their separation factor, which is equal to the ratio of their distribution coefficients. The further the separation factor is from unity the easier it is to separate the two solutes.

The process of solvent extraction is an important method for the separation of rare-earths. It is important because it has advantages over the older methods of fractional crystallization and ion exchange. Fractional crystallization, although capable of producing high purity rareearths, is no longer of commercial importance because of the time consuming nature of the process and the associated high operating costs. Therefore, the two processes of commercial 
importance are solvent extraction and ion exchange.

Several articles and books $(28,4,5)$ have qualitatively compared these two processes. The authors of these references conclude that solvent extraction has the following advantages: it can operate on very concentrated solutions, it has large throughputs with small plants, and it is a continuous process and thus capital and operating costs are usually lower. The disadvantages are that close control must be exercised to obtain high purities and the plants are usually inflexible because they are designed for a given separation. Ion exchange on the other hand must work with less concentrated solutions, capital and operating costs are high because of the batch nature of the process, and it usually requires a number of months to complete a given separation; however, ion exchange equipment is more flexible and higher purities can be obtalned by this process than with solvent extraction.

Solvent extraction does have a number of advantages over ion exchange, however, it does not have the advantage in the important area of product purity. For solvent extraction to compete in terms of purity rigid control must be exerclsed un llie extractor. 


\section{Extractor Control}

For many years feedback control has been an acceptable means of control for chemical processes. The one problem with feedback control is that action to correct an upset in an input variable is not taken until the effect of the upset is sensed in the output. Therefore, for a process with large dead times or transport delays such as an extractor, feedback control may not be an adequate means of regulation. The type of control needed for a process like an extractor is predictive control.

Predictive or feedforward control is a control method where corrective action is initiated at the time of the upset so that the output variable can be maintained at its set point. The change in the measured input variable is fed to a model of the process which calculates the new value for the control variable which will hold the output variable at its set point. The process model consists of a steady state gain term and very often a dynamic compensation term. The steady state gain term gives the steady state value for the control variable that will eliminate any final offset in the output variable. Dynamic compensation is included in those cases where transients in the output variable which result from using only a steady state gain term are too large and must be eliminated or reduced. There are various methods of obtaining the predictive 
control model. In this work the steady state gain term was a Iinear regression equation which was obtained using data from a steady state analysis of the extractor: The dynamic compensation portion of the predictive control model was determined from measured input and control variable dynamic response information. This dynamic response information was used to determine a transfer function relating the control variable to the measured input variable.

A feedback trimmer was also included in the control scheme to eliminate any final offset in the output variable. since the steady state gain term was a linear approximation to the actual system the calculated steady state value for the control variable would not return the output variable to its desired set point after an upset without the feedback trimmer.

A desirable feature of this predictive control method is that the mathematics associated with the control scheme are very simple. The scheme is such that it can be implemented with a small control computer.

\section{Rare-Earths}

Rare-earths, or lanthanides, comprise the series of chemically similar elements with atomic numbers 57 through 71. These elements have nearly identical chemical properties in an aqueous solution. Thus the separation of rare- 
earth mixtures into their individual components has drawn much attention.

A great deal of rare-earth research has been concerned with determining the extraction characteristics of the rareearths with various solvents and in determining the equilibrlum relationships for the rare-earths with these solvents. The equilibrium relationships are usually complex because of the interaction effects the rare-earths have on each other in solution. The distribution coefficient for a particular rare-earth in a mixture of rare-earths is usually a function of not only its own aqueous phase concentration but also the aqueous phase concentration of the other rare-earths in the mixture. It is the equilibrium relationships that are needed in designing extractors as well as in studying their dynamic response and control characteristics.

Many new engineering applications for rare-earths have been found $(13,15,28)$. Some of the more important uses are as alloying agents with metals to impart certain desirable qualities such as hardness, tensile strength, impact strength, etc. In the petroleum industry they are being used as catalysts. The high neutron-absorption cross section characteristics of several rare-earths have led to their use in control rods in nuclear power generators. Because of these and other uses the demand for rare-earthis is 
expected to increase in the future (23).

The rare-earth system studied in this work was $\mathrm{CeCl}_{3}-\mathrm{NaCl}_{3}-\mathrm{SmCl}_{3}-\mathrm{HCl}-\mathrm{H}_{2} \mathrm{O}$. The solvent used was di(2-ethylhexyl) phosphoric acid, D2EHPA, in Amsco Odorless Mineral Spirits. The extractor separates samarium into the extract stream and cerium and neodymium into the raffinate stream. The equilibrium relationships for this system were determined by Ioannou et al. (14).

\section{Objectives}

The objectives of this work were to develop a simulation of the extractor and to obtain the predictive control model using results from the simulation. Two requirements of the simulation were that it handle actual rare-earth equilibrium data and that it include flow rate lags to account for the transport delays in an extractor. The objective of the control study was to obtain a predictive control model that would control the extractor for both feed concentration and feed flow rate changes. The control criteria were that samarium purity in the extract and samarium recovery both remain above the 99 percent level. 


\section{REVIEW OF RELATED WORK}

\section{Extractor Simulation}

Research on the analysis and simulation of extraction columns was started about twenty years ago. Most of the early studies were concerned with continuous contact extractors such as spray, packed or pulsed columns and not stagewise ones like mixer-settlers.

A thorough review of the literature on the analysis and simulation of extraction systems preceding 1968 was presented in an article by Pollock and Johnson (24). All the articles reviewed were concerned with simple columns with both feed input and product removal at the ends; none were concerned with center fed extractors. None of the numerical studies reviewed pertained to mixer-settler extractors. Because of the absence of studies on center fed extractors and because of the scarcity of control studies, Pollock and Johnson (24) felt that the direct application of the works reviewed to commercial extractors was difficult. One of the first numerical studies of the transient response of an end fed, mixer-settler extractor was carried out in 1966 by Halligan and Smutz (11) who studied the startup behavior of the extractor. Four models for the flow characteristics in the extractor stages were used in the study. Calculated and experimental results were compared and it was found that the model which gave the best agreement 
with the experimental results assumed perfect mixing in the aqueous phase of the settling chamber and plug flow in the organic phase of the chamber. The responses based on all four models tended to converge to the same response as the number of stages were increased.

The first study of the dynamic response of a center fed, mixer-settler extractor was reported by Lowe (17) in 1967 as part of a study of optimum startup and shutdown procedures for an extractor processing nuclear fuels. The purpose was to study nuclear criticality safety problems during transient periods of operation. The extractor was simulated by a set of unsteady state material balances and also allowed for the inclusion of experimentally determined equilibrium relations. Considering the simplicity of the model used, Lowe obtained reasonable agreement between calculated and experimental concentration profiles following an upset in the extractor.

Erskine (10) simulated the dynamic response of a center fed, mixer-settler extractor separating rare-earths in the first predictive control study of an extractor. The simulation allowed for variable flow rates and holdups but used a linear approximation to the equilibrium data. The ability of the simulation to move the extractor from one steady state to another was demonstrated.

A more detailed simulation of a mixer-settler extractor 
was done by Cadman and Hsu (3). The simulation was based on differential equations which described the mixing and settling chambers of each stage separately. Nonlinear" models for both constant and nonconstant holdups in the mixing and settling chambers were presented. The frequency domain method of solution required the linearization of all models. The mathematics associated with the simulation were quite complicated and the application of this method to an extractor with many stages would be difficult.

Other extraction studies were by Souhrada et al. (26) who were the first to study extractor startup behavior using a. stagewise contact model with nonideal stages and backmixing, and Cheng (8) who demonstrated the usefulness of unsteady state simulations in the design of an extractor.

\section{Predictive Control}

Predictive control was used in this work to control the extractor. The classical presentation of predictive control theory was by Bollinger and Lamb $(1,2)$. Their articles presented an analytical derivation of the predictive control equations from the differential equations describing the system. The restrictions placed on the differential equations were that they be linear and time invariant. Applications of this predictive control theory to various chemical processes were presented by Bollinger 
and Larnb $(1,2)$, T1nker and Lamb (27), and Luyben and Lamb (21).

Haskins and Sliepcevich (12) and Luyben (20), in their control studies of chemical reactors, showed that Bollinger and Lamb's $(1,2)$ requirement of a linear dynamic model was not necessary in order to obtain an analytical solution for the predictive control equations from nonlinear dynamic models. They compared the results from the nonlinear theory to those from the linear theory and discussed the differences. Haskins and Sliepcevich (12) concluded that the linear theory predictive models were able to give good control for even the severest disturbances and they recommended the use of the nonlinear theory only in those cases where the process simulation was not very accurate. On the other hand, Luyben (20) considered the use of the nonlinear theory to have improved the predictive control responses.

Lupfer and Parsons (18) and MacMullin and Shinskey (22) present predictive control schemes for a distillation column where the steady state gain term was based on a column material balance. The dynamic compensation term was de-. termined from a study of actual dynamic responses of the column. Both control schemes were implemented on actual distillation columns and improvements in both column operation and economic return were considered excellent. Other studies concerned with the predictive control 
of distillation columns were reported by Luyben (19) who was concerned in this study with the dependence of the steady state gain term on feed composition, and by Distefano et al. (9) whose predictive control equation for reflux ratio was determined by placing restrictions on the nonlinear process model.

The first predictive control study of a mixer-settler extractor was done by Erskine (10). Two different predictive control schemes were presented in this work. Both methods were based on a steady state analysis of the extractor. The first used a linear regression model which predicted the steady state value for the output variable corresponding to the measured input variable upset. The predicted value for the output variable was sent to a controller which generated a value for the control variable. The other method used a linear regression model which predicted the steady state value for the control variable. No dynamic compensation of this model was done. However, a feedback trimmer was included to eliminate any final offset in the output variable which results from inaccuracies in the steady state gain model. The predictive control schemes, using reflux ratio as the control variable, were shown to give considerable improvement over feedback control.

Another predictive control study of an extractor was by Cadman and Hsu (3). Predictive control transfer functions 
were theoretically designed using linearized transient models of the process. The study was only partially successful because of problems encountered in accurately calculating the control variable from the control transfer functions. 


\section{THEORY}

Extractor simulation

The nonlinear, time varying differential equations necessary to describe a mixer-settler extractor were derived by making an unsteady state material balance around a typical extractor stage, $j$, and assuming ideal stages. This assumption is supported by the work of Rahn and Smutz (25) and others who have shown experimentally that stage efficiencies of nearly 100 percent can be obtained in a well-designed mixer-settler extractor.

Other assumptions made in the derivation were that the flow rate responses could be described by first order lags, that the total holdup in each stage was constant, that the holdup of each of the phases within the stage was proportional to the flow rates, and that the steady state flow rates did not vary from stage-to-stage.

The unsteady state material balance for component i in stage $j$, shown in Figure 1 , can be written as,

$$
\begin{aligned}
& H_{j} \frac{d}{d t} X_{i, j}+x_{i, j} \frac{d}{d t} H_{j}+h_{j} \frac{d}{d t} Y_{i, j}+Y_{i j} \frac{d}{d t} h_{j} \\
& =s_{j-1} X_{i, j-1}-s_{j} X_{i, j}-E_{j} Y_{i, j}+E_{j+1} Y_{i, j+1}+F X_{i}^{f} \cdot
\end{aligned}
$$

In this equation the individual phase accumulation terms have been differentiated to give the concentration and 


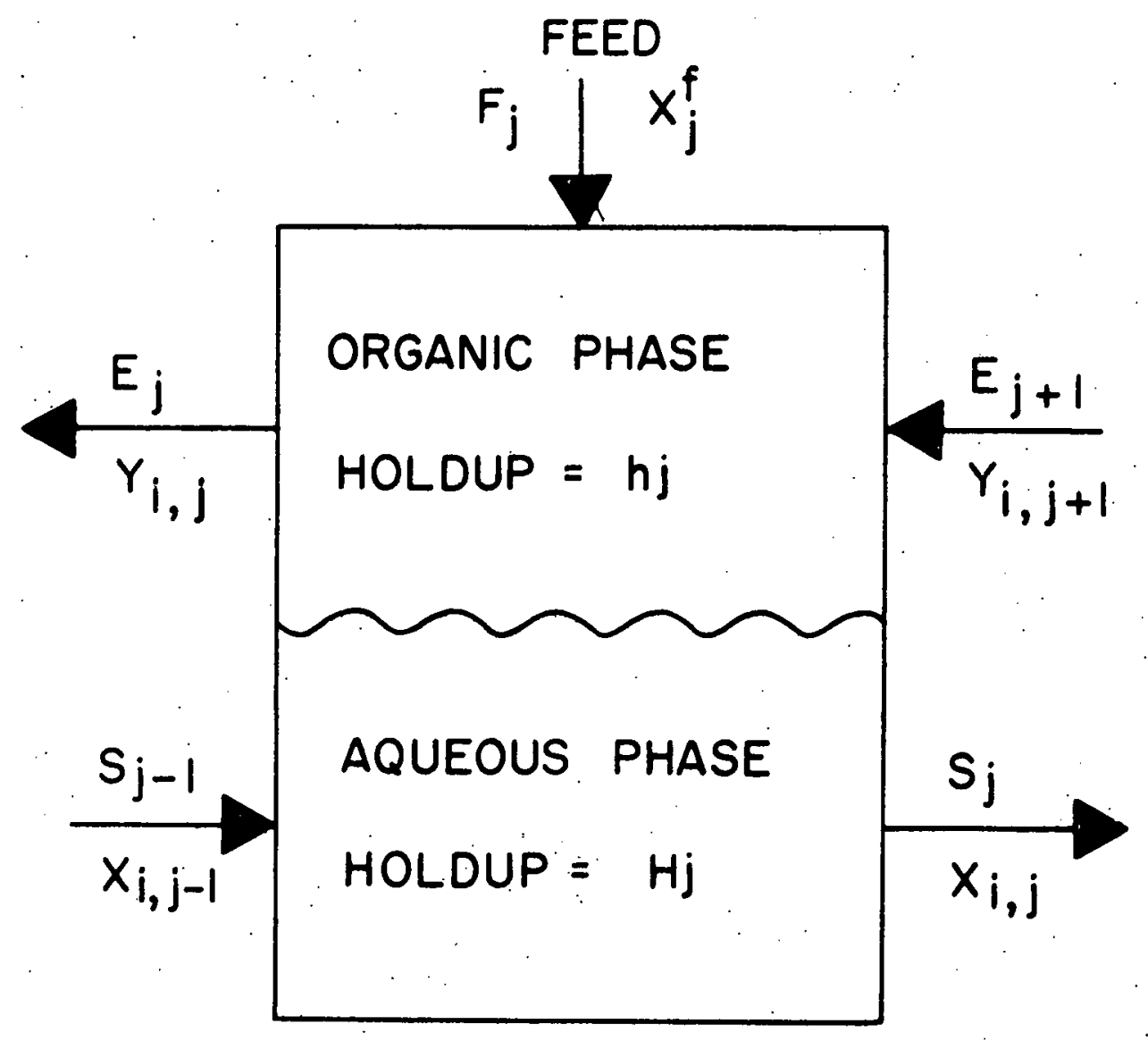

$j^{\text {th }}$ EXTRACTOR STAGE

Figure 1. General stage of a mixer-settler extractor 
holdup derivatives. The last term in the equation is zero for all stages except the feed stage.

Because the equations were solved by numerical integration, it was necessary to rewrite them in a form suitable for computation. Using a backwards finite difference approximation, the two concentration derivatives in Equation 1 can be written,

$$
\begin{aligned}
\left.\frac{d}{d t} x_{i, j}\right|_{t+\delta t} & =\frac{x_{i, j, t+\delta t}-x_{i, j, t}}{\delta t} \\
\left.\frac{d}{d t} Y_{i, j}\right|_{t+\delta t} & =\frac{Y_{i, j, t+\delta t}-Y_{i, j, t}}{\delta t}
\end{aligned}
$$

The holdup derivatives are left in differential form and calculated by a procedure explained later. These finite difference approximations can be substituted into Equation 1, and the result rearranged to give,

$$
\begin{aligned}
& H_{j, t+\delta t} x_{i, j, t}+h_{j, t+\delta t} Y_{i, j, t}+\delta t F_{t+\delta t} x_{i, t+\delta t}^{f} \\
& =\left.\left[-\delta t s_{j-1}\right]\right|_{t+\delta t} x_{1, j-1, t+\delta t} \\
& \quad+\left.\left[H_{j}+\delta t\left(s_{j}+\frac{d}{d t} H_{j}\right)\right]\right|_{t+\delta t} x_{i, j, t+\delta t} \\
& +\left.\left[h_{j}+\delta t\left(E_{j}+\frac{d}{d t} h_{j}\right)\right]\right|_{t+\delta t} Y_{i, j, t+\delta t}
\end{aligned}
$$




$$
+\left.\left[-\delta t E_{j+1}\right]\right|_{t+\delta t} Y_{i, j+1, t+\delta t}
$$

An additional subscript has been added to indicate time dependence. This equation has been written so that all the concentrations on the left hand side, LHS, except the feed term, are evaluated at $t$ and those on the right hand side, RHS, at $t+\delta t$. The coefficients on the RHS and the feed terms are evaluated at $t+\delta t$ because a backward difference approximation was used.

The distribution equation,

$$
Y_{i, j, t}=K_{i, j, t} X_{i, j, t} \quad,
$$

can be used to eliminate the organic phase concentrations from Equation 3. The distribution coefficients in Equation 4 are dependent upon the aqueous phase rare-earth, concentration and the aqueous phase acid concentration and can be represented in functional form as,

$$
k_{i, j, t}=k\left(x_{i, j, t} ; A_{j, t}\right)
$$

The calculational procedure for $k_{i, j, t}$ will be discussed. later in the section on the description of the rare-earth system. Using this definition for the distribution coefficients, Equation 3 becomes, 


$$
\begin{aligned}
& {\left[H_{j, t+\delta t}+h_{j, t+\delta t} K_{i, j, t}\right] x_{i, j, t}+\delta t F_{t+\delta t} x_{i, t+\delta t}^{f}} \\
& =\left.\left[-\delta t s_{j-1}\right]\right|_{t+\delta t} x_{i, j-1, t+\delta t}+\left[H_{j}+h_{j} K_{i, j}\right. \\
& \left.+\delta t\left(s_{j}+E_{j} K_{i, j}+\frac{d}{d t} H_{j}+\frac{d h_{j}}{d t} K_{i, j}\right)\right]\left.\right|_{t+\delta t} x_{i, j, t+\delta t} \\
& +\left.\left[-\delta t E_{j+1} K_{i, j+1}\right]\right|_{t+\delta t} x_{i, j+1, t+\delta t}
\end{aligned}
$$

The only unknown quantities in Equation 6 are the aqueous phase rare-earth concentrations and the distribution coefficients. The flow rates, holdups, and holdup derivatives evaluated at $t+\delta t$ are known because they are found from relations presented below which are independent of $x_{i, j, t+\delta t}$ and $k_{i, j, t+\delta t^{\bullet}}$. A simple direct iteration between $x_{i, j, t+\delta t}$ and $k_{i, j, t+\delta t}$ can then be used to find the concentrations after each time step.

Since Equation 6 applies to each stage of the extractor, it represents a set of $i x j$ simultaneous algebraic equations which can be written as,

$$
\underline{C}_{i}=\underline{D}_{i} \underline{x}_{i}
$$

Here $C_{i}$ is a constant vector which represents the LHS of Equation $6, \underline{x}_{i}$ is the concentration vector, and $\underline{D}_{i}$ is the matrix of coefficients of the concentrations. The matrix 
$\underline{D}_{i}$ is tridiagonal and the method of Thomas as presented in Lapidus (16) can be used to solve for the $x_{i, j, t+\delta t^{*}}$ The aqueous and organic flow rate responses were assumed to be represented by first order lags,

$$
\begin{array}{ll}
\text { Organic Phase: } & \tau_{j}^{E} \frac{d E_{j}}{d t}=E_{j+1}-E_{j}, \\
\begin{array}{l}
\text { Aqueous Phase- } \\
\text { Nonfeed Stage: }
\end{array} & \tau_{j}^{S} \frac{d S_{j}}{d t}=s_{j-1}-s_{j}, \\
\begin{array}{l}
\text { Aqueous Phase- } \\
\text { Feed Stage: }
\end{array} & \tau_{f}^{S} \frac{d S_{f}}{d t}=s_{f-i}-s_{f}+F
\end{array}
$$

Here the $\tau^{\prime} s$ are the time constants. These differential equations can be solved numerically to find the change in flow rates following an upset in the column.

The total volume in each stage was assumed constant and the holdup of each phase was assumed to be proportional to the flow rates. Under these conditions the expression relating the aqueous phase holdup to the total stage volume, $v$, and the organic phase holdup of stage $j$ is,

$$
\mathrm{H}_{j}=\mathrm{V}-\mathrm{h}_{j}
$$

Differentiation of this equation with respect to time shows that one holdup derivative is the negative of the other so. it is necessary to calculate only one holdup derivative. The derivative $\mathrm{dH}_{\mathrm{j}} / \mathrm{dt}$ can be determined by using the definition 
of holdup, $\mathrm{H}_{j}$, in terms of flow rates. The aqueous phase holdup is calculated by multiplying the total stage volume by the ratio of all the aqueous flows into the stage to the total flow into the stage. The mathematical expression for $\mathrm{H}_{j}$ is,

$$
\begin{array}{ll}
\text { Nonfeed Stage: } & H_{j}=\frac{S_{j-1} \cdot V}{\left(S_{j-1}+E_{j+1}\right)} \\
\text { Feed Stage: }: & H_{j}=\frac{\left(S_{j-1}+F\right) \cdot V}{\left(S_{j-1}+E_{j+1}+F\right)} .
\end{array}
$$

Differentiating these equations with respect to time gives Equations lla and $11 \mathrm{~b}$ which can be used to obtain the holdup derivatives,

Nonfeed stage:

$$
\frac{d H_{j}}{d t}=\frac{\left(s_{j-1}+E_{j+1}\right) \cdot v \cdot \frac{d s_{j-1}}{d t}-s_{j-1} \cdot v \cdot\left(\frac{d s_{j-1}}{d t}+\frac{d E_{j+1}}{d t}\right)}{\left(S_{j-1}+E_{j+1}\right)^{2}}
$$

Feed Stage:

$$
\frac{d H_{j}}{d t}=\frac{\left(s_{j-1}+E_{j+1}+F\right) \cdot v \cdot \frac{d s_{j-1}}{d t}-\left(s_{j-1}+F\right) \cdot v \cdot\left(\frac{d s_{j-1}}{d t}+\frac{d E_{j}+1}{d t}\right)}{\left(s_{j-1}+E_{j+1}+F\right)^{2}} .
$$


The flow rate derivatives needed here are obtained from Equation 8 .

As mentioned earlier the distribution coefficient, $k_{i, j, t^{\prime}}$ is a function of the aqueous phase rare-earth concentration and the aqueous phase hydrochloric acid concentration. The acid concentration in each stage is not constant because for each mole of rare-earth extracted into the organic phase, approximately three moles of acid are added to the aqueous phase due to the extraction reaction. Therefore a nonsteady stage aqueous phase acid balance is required in the simulation.

The unsteady state acid balance for stage $j$ is,

$$
\frac{d}{d t}\left[H_{j} A_{j}\right]=S_{j-1} A_{j-1}-S_{j} A_{j}-3 *\left(\sum_{i} \frac{d}{d t} x_{i, j}\right) H_{j}
$$

Equation 12 can be converted into a useful computational form by differentiating the LHS and using forward finite difference approximations for the rare-earth and acid concentration derivatives,

$$
\begin{aligned}
A_{j, t+\delta t}= & A_{j, t}+\delta t\left[\frac{S_{j-1}}{H_{j}} A_{j-1}-\frac{S_{j}}{H_{j}} A_{j, t}\right. \\
& \left.-\frac{A_{j, t}}{H_{j}} \frac{d H_{j}}{d t}\right]\left.\right|_{t}-\underset{i}{3 * \sum}\left(x_{i, j, t+\delta t}-x_{i, j, t}\right) .
\end{aligned}
$$


Predictive Control

Predictive or feedforward control is a method of control whereby corrective action to maintain an output variable at its set point value can be initiated as soon as an upset is sensed in any measured input variable. In contrast to predictive control, feedback control requires that the output variable deviate from its set point before any action can be taken to restore it to the set point position. In most applications, feedback control is adequate for chemical process regulation. It is also usually the most economical control strategy to use. However, for systems with large time constants or with long dead times it may be useful to employ a predictive control system where inputs which are expected to change are continuously monitored. When a change occurs in a measured input, this change is fed to a model of the process and a new value of the control variable computed which will hold the output of the process at the desired value. Predictive control is more restrictive than feedback control because it can only control upsets in those input variables that are measured. If there are changes in unmeasured input variables which effect the outputs, these must be controlled by feedback control. Predictive control models may consist of two distinct parts. One is a steady stage gain term and the other a dynamic term. The steady state gain term gives the final 
steady state value for the control variable which is needed to eliminate any offset in the output variable due to a change in measured input variable. If the predictive control model contains only a steady state term, then the control action consists of moving the control variable immediately to its new computed value following a change in the input variable. This will produce transient effects in the output. If these transients are not sufficiently large to be considered detrimental, then a steady state predictive control model is adequate. If, however, the transients are important, then dynamic compensation must be added to the control model.

In this study the measured input variables were feed concentration and feed flow rate. The control variable was the solvent flow rate, and the output variables were samarium purity in the extract stream; $\mathrm{x}_{\mathrm{p}^{\prime}}$ and samarium recovery, Re. The control criteria used was that both extract purity and samarium recovery be kept at values greater than 99 percent.

In classical predictive control theory there is a requirement that there be the same number of control variables as there are output variables. However in this work it was possible because of the nature of the system studied to have two output variables, extract purity, $x_{p}$ and samarium recovery, Re, but only one control variable, solvent flow 
rate, E. These unique characteristics will be explained below.

Steady state gain

The steady state gain term used for the predictive control model in this work was obtained by fitting a linear regression equation to the response surface relating steady state solvent flow rate as a function of samarium feed concentration, feed flow rate, recovery, and extract purity. The form of the equation is,

$$
E_{p}=a_{1} x_{S m}^{f}+a_{2} F+a_{3} x_{p}+a_{4} R e+a_{5}
$$

where the $a_{i}$ are the linear regression coefficients. The data needed to calculate the regression coefficients were obtained by choosing three values of $E, x_{S m}^{f}$ and $F$ in the neighborhood of the desired steady state and solving the extractor simulation equations to find the corresponding steady state values of $\mathrm{x}_{\mathrm{p}}$ and $\mathrm{Re}$ for all combinations of these points.

Equation 14 relates the control variable to the measured input variables and the output variables. In a predictive control equation the values for these output variables must be their set point values. 
Dynamic compensation

Dynamic compensation was added to improve the transient response of the extractor and control system. To obtain the necessary information for developing this term the open loop response of the output variable must be known for an upset in the input variable and in the control variable. Figure 2 shows hypothetical response curves for these two upsets. The curves have been normalized in terms of the output variable so that the steady state gain for the approximating transfer function that must be found for each curve is unity. The form of the approximating function depends on the nature of the response curve. For the response curves shown in Figure 2 the functions may be chosen as,

$$
\begin{aligned}
& \frac{O(s)}{E(s)} \cong \frac{e^{-g s}}{\left(1+\tau_{p} s\right)} \\
& \frac{O(s)}{I(s)} \cong \frac{1}{\left(1+\tau_{q} s\right)\left(1+\tau_{r} s\right) \ldots}
\end{aligned}
$$

The response curve for the control variable upset resembles a first order response with an initial dead time. The Sshaped curve for the measured input variable is best approximated by a higher order transfer function. In most cases the determination of the best approximating transfer function is a trial and error procedure.

After the transfer functions have been obtained they 


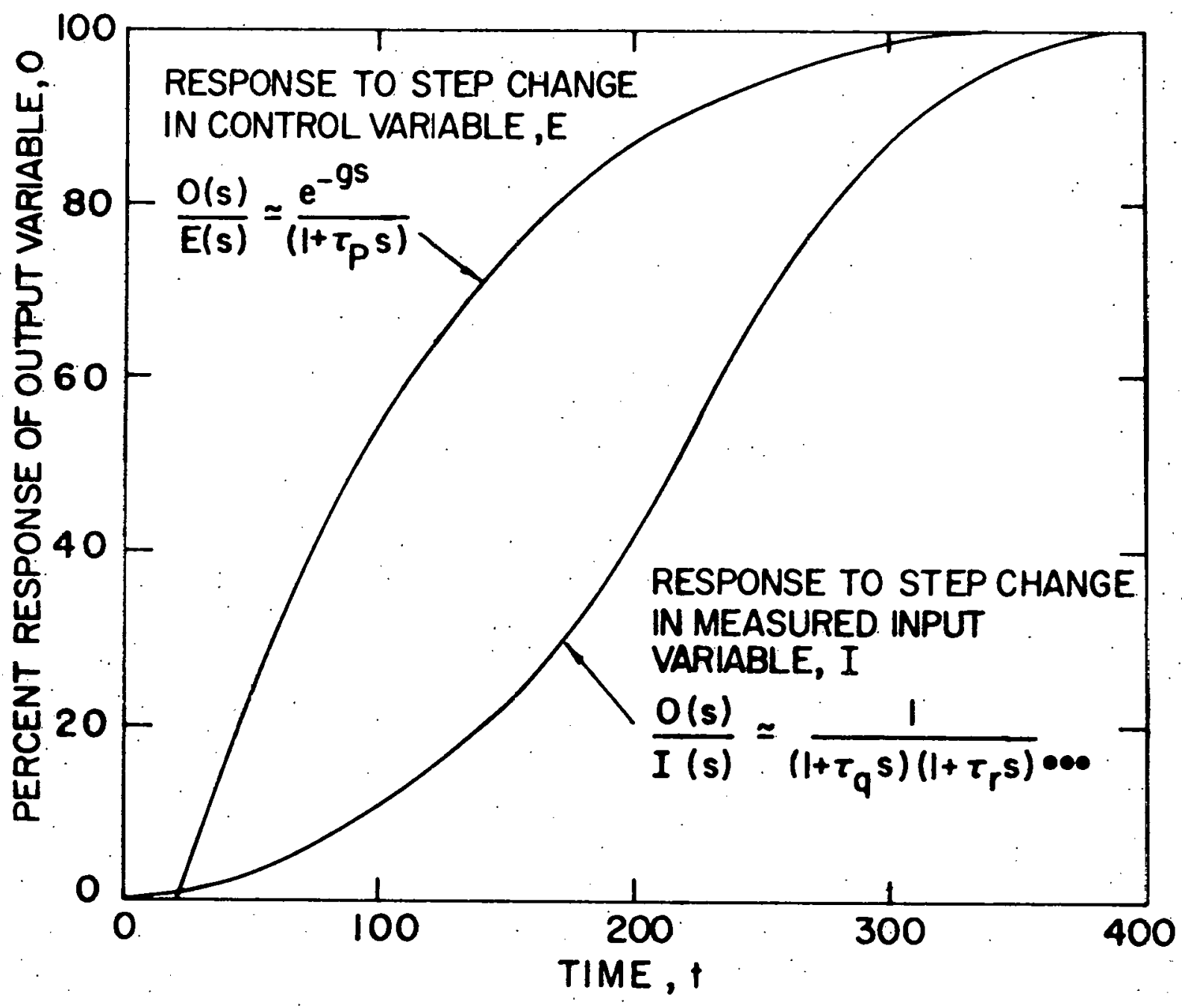

Figure 2. Hypothetical response curves 
must be combined to eliminate the output variable and obtain a new transfer function relating $E(s)$ to $I(s)$. This is done by dividing Equation $15 \mathrm{~b}$ by $15 \mathrm{a}$ giving,

$$
\frac{E(s)}{I(s)} \cong \frac{e^{g s}\left(1+\tau_{p} s\right)}{\left(1+\tau_{q} s\right)\left(1+\tau_{r}^{s}\right) \ldots} .
$$

Equation 16 is the final dynamic transfer function. It is then inverted into the time domain, using a step upset, $I / s$, for $I(s)$, to give the solvent flow rate, $E$, as a function of time, $E_{D}(t)$. The steady state gain for this transfer function is again unity because the steady state gains for the transfer functions from which it was determined were unity. This dynamic term is combined with the steady state gain predictive control term to give the control variable change as a function of time,

$$
E_{p}\left(t ; E_{s}\right)=E_{s}-E_{D}(t) \cdot\left(E_{s}-E_{p}\right)
$$

Here $E_{S}$ is the value of $E$ at the time it was sensed that a measured input variable had changed. The dynamic term multiplies the difference between the $E$ at the time of the upset and its predicted value. The difference is used because the flow rate must be changed from $E_{s}$ to $E_{p^{*}}$

The steady state gain term in Equation 17 is not an exact model of the steady state characteristics of the extractor around the desired operating point. It is a 
linearized approximation obtained by a least squares fit of the response surface. Thus the value of $\mathrm{E}_{\mathrm{p}}$. calculated from Equation 14 will probably not give the exact value of solvent flow rate needed for the upset and some final offset in the output variable can be expected. A feedback trimmer was included in the control scheme to eliminate this offset. Proportional-integral control was used for the trimmer. The equation for the feedback trimmer is,

$$
E_{T}\left(X_{p}, R_{p}\right)=K_{A} \varepsilon+1 / \tau_{I} \cdot \int_{0}^{t_{0}} \varepsilon d t
$$

where $\varepsilon$ is the amount the output variable deviates from its set point.

The complete equation for the control model is,

$$
E(t)=E_{p}\left(t_{i} E_{s}\right)+E_{T}\left(X_{p}, R_{p}\right)
$$

$E(t)$ is the solvent flow rate set by the flow controller on the extractor.

\section{Calculational Procedure}

The calculational steps given below represent the sequence followed when the predictive control model is used to correct for a step change in one of the measured input variables. The extractor simulation equations are used to represent the extractor: 
1. Begin the calculation with known steady state values for the aqueous phase rare-earth and acid concentrations, the feed concentrations and feed flow rate, and the stage flow rates and holdups.

2. Obtain values for the initial distribution coefficients, $k_{i, j}, t^{\prime}$ from Equation 5 .

3. Introduce an upset by changing the value of one of the measured input variables.

4. Calculate the new flow rates and holdups at $t+\delta t$ from Equations 8 and 10.

5. Determine the flow rate derivatives and the holdup derivatives from Equations 8 and 11 .

6. As a first approximation to the distribution coefficients at $t+\delta t$, which are unknown, use the values at $t$ to calculate the coefficients $C_{i}$ and $D_{i}$ in Equation 7, but on all successive iterations use the values calculated from the previous iteration as the assumed values for the distribution coefficients at $t+\delta t$ and calculate the coefficients $\underline{C}_{i}$ and $\stackrel{D}{=}_{i}$.

7. Using the method of Thomas find $x_{i, j, t+\delta t}$ from Equation 7 .

8. From Equation 13 calculate the acid concentration, $A_{j, t+\delta t^{*}}$ 
9. Determine the new calculated value for $k_{i, j, t+\delta t}$ using $x_{i, j, t+\delta t}$ from, step 7 and $A_{j, t+\delta t}$ from step 8 .

10. Compare the assumed and calculated values for $k_{i, j, t+\delta t}$ and determine if corresponding distribution coefficients have converged to within a specified tolerance.

11. If the distribution coefficlents have not converged repeat steps 6 through 10 using the distribution coefficients calculated in step 9 as the new estimate for the coefficients. If they have converged calculate the values of the output variables.

12. Use the steady state material balance equations, Equation 1 with the derivatives equal to zero, to see if the extractor transient has damped out.

13. If the steady state equations are satisfied the calculations are stopped. If they are not satisfled, reinitilize the rare-earth concentrations, acid concentrations, and distribution coefficients so that the calculation procedure can be repeated.

14. Use the control equation, Equation 19, to calculate a new value for solvent flow rate.

15. Repeat the calculational procedure starting with step 4 . 
In step 12 the extractor steady state material balance equations were used to determine if the transient response had damped out. This method made it possible to use the unsteady state equations to determine steady state values for extractor output variables from an arbitrary set of input variables. This technique was also used to obtain the data from which the coefficients for the predictive control steady state gain equation were calculated. When using the simulation to determine steady state conditions steps 3 through 5 and step 14 were left out of the calculational procedure. These steps were needed only when dynamic or controlled responses were desired. 


\section{DESCRIPTION OF RARE-EARTH SYSTEM, EXTRACTOR, AND EXTRACTOR CHARACTERISTICS}

The Rare-Earth System

The rare-earth feed in this study was a mixture of cerium, neodymium, and samarium chlorides in an $\mathrm{HCl}$ solution. The solvent was di-(2-ethylhexyl) phosphoric acid, D2EHPA, in Amsco Odorless Mineral spirits. Mathematical expressions for the equilibrium data were determined by Ioannou et al. (14).

The equilibrium relationships for this system are complex, as they are for most other rare-earth systems. Individual rare-earth organic phase concentration is not only a function of its own aqueous phase concentration but also a function of the concentrations of the other rareearths and of the acid concentration. These characteristics make correlation of the equilibrium data very difficult: The procedure devised by Ioannou et al. (14) to determine the rare-earth organic concentrations from known values of the aqueous phase concentrations is as follows:

1. Compute the quantity $Y_{i}^{*}=f\left(X_{T^{\prime}} A\right)$ at $X_{T}$ and $X_{T}$ reference. $Y_{i}^{\star}$ is the single component organic phase concentration assuming all the rare-earth in the aqueous phase was rare-earth species 1 and $x_{T}$ is the total rare-earth concentration in the aqueous phase.

2. Compute $\mathrm{X}_{\mathrm{T}^{\prime}}$ the total rare-earth concentration in 
the organic phase, for the Sm-Nd binary system at $\mathrm{X}_{\mathrm{T}}$ and $\mathrm{x}_{\mathrm{T}}$ reference.

3. Compute $\mathrm{Y}_{\mathrm{T}}$ for the ternary system at $\mathrm{X}_{\mathrm{T}}$ and $\mathrm{X}_{\mathrm{T}}$ reference.

4. Use the separation factor $\beta_{i, j}$ to find $Y_{i}$ from $Y_{T}$ ternary. The separation factor is the ratio of the distribution coefficients for components $i$ and $j$. A large $\beta_{i, j}$ would mean that component $i$ is extracted into the organic phase more easily than component $j$. The separation factor is not actually a constant, but its variation over the range of concentrations in this work is small enough to assume it to be constant. The values for $\beta_{i, j}$ are,

$$
\begin{aligned}
& \beta_{\text {Sm, Ce }}=19.5 \\
& \beta_{\text {Sm, Nd }}=9.06 \\
& \beta_{\text {Na, Ce }}=2.16 .
\end{aligned}
$$

5. Finally, compute the individual rare-earth distribution coefficients, $K_{i, j}=Y_{i, j} / X_{i, j}$.

\section{The Extractor}

The extractor simulated in this study was a 14 stage, center fed, mixer-settler extractor. The flow patterns for the rare-earths in the extractor are shown in Figure 3. Samarium is removed in the extract stream and the cerium and neodymium in the raffinate stream. In the extract section, 

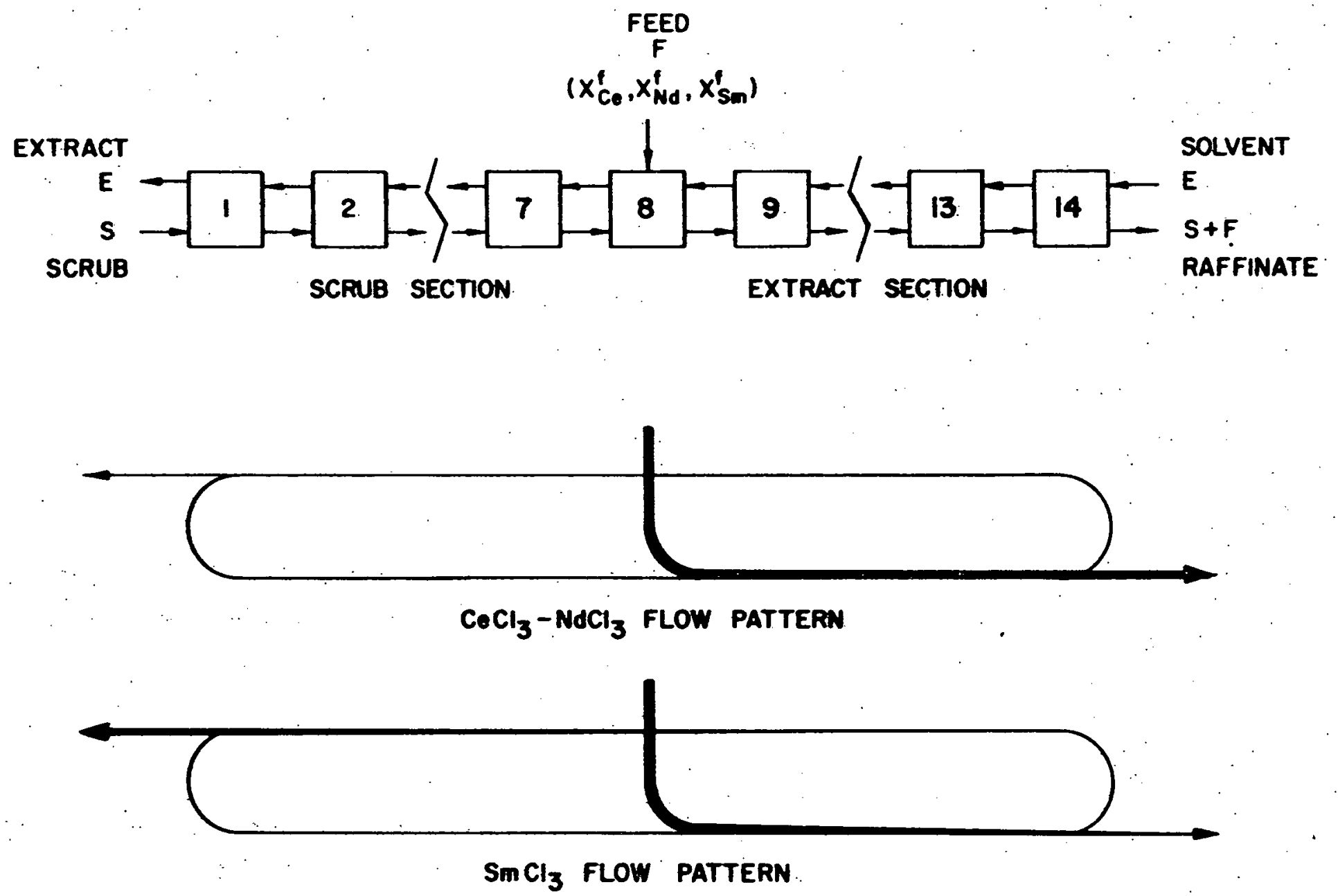

Figure 3. Flow patterns of the rare-earths in the extractor 
which corresponds to the stripping section in a distillation column; nearly all of the samarium and some of the cerium and neodymium is extracted into the organic phase. This organic phase then enters the scrub section, which corresponds to the rectifying section in a distillation column, where most of the cerium and neodymium and a little samarium is back-extracted into the aqueous phase thus leaving an extract stream containing almost pure samarium. The rare-earth feed concentrations were chosen to represent a monazite ore from which the thorium, lanthanum, and some of the cerium have been removed by previous separation steps. The concentrations of the rare-earth chlorides in the feed were,

$$
\begin{aligned}
& \mathrm{x}_{\mathrm{Ce}}^{\mathrm{f}}=0.5 \text { moles } / \text { liter } \\
& \mathrm{x}_{\mathrm{Nd}}^{\mathrm{f}}=0.375 \text { moles } / \text { itier } \\
& \mathrm{x}_{\mathrm{Sm}}^{\mathrm{f}}=0.375 \text { moles } / \text { iter }
\end{aligned}
$$

The feed acid concentration was 0.5 moles/liter--an average of the values used by Ioannou et al. (14) in the determination of the equilibrium data. The feed flow rate was 5:0 liters/min.

The concentrations of di-(2-ethylhexyl) phosphoric ac1d, D2EHPA, in the solvent stream was 1.0 mole/liter and the hydrochloric acid concentration in the scrub stream was 
0.5 moles/liter.

With the number of stages, feed conditions, and solvent and scrub stream concentration specified the unsteady state extractor simulation was used to determine steady state solvent and scrub flow rates that would give the desired separation. The procedure consisted of picking values for the flow ratios, $\alpha$ and $\beta$, and then calculating the corresponding steady state values for extract purity and samarium recovery. The flow rate ratios determined were,.

$$
\begin{aligned}
& \alpha=0.87 \\
& \beta=1.0
\end{aligned}
$$

The corresponding solvent and scrub flow rates were,

$$
\begin{aligned}
& E=38.46 \text { liters } / \mathrm{min} \\
& S=33.46 \text { liters min }
\end{aligned}
$$

For the above operating conditions the values of the two output variables were,

$$
\begin{aligned}
& x_{p}=99.28 \% \\
& \operatorname{Re}=99.96 \% .
\end{aligned}
$$

\section{Extractor Characteristics}

There are certain characteristics associated with this extraction process which, along with the control specifications placed on the output variables, made it possible to 
control two output variables with one control variable. These properties were noticed during examination of the data used in the calculation of the coefficients of the predictive control steady state gain equation. The data showed that if either samarium feed concentration; $\mathrm{x}_{\mathrm{Sm}^{\prime}}$ or feed flow rate, F, decreased from their desired operating values that extract purity, $x_{p^{\prime}}$ fell but that samarium recovery, Re, rose. Conversely it was noticed that if either input variable increased then $R e$ fell and $X_{p}$ rose. This can be explained as follows.

Consider a decrease in the samarium feed concentration. Since there is less samarium to be removed, there is now an excess amount of solvent available and thus nearly all the samarium and a larger proportion of the neodymium and cerium are extracted into the organic phase. This allows samarium recovery to rise slightly but lowers extract purity. For an increase in $\mathrm{x}_{\mathrm{Sm}}^{\mathrm{f}}$ more samarium enters the extractor but there is not enough solvent to remove it all. Therefore some of $1 t$ leaves in the raffinate stream and the recovery is lowered. The extract purity rises slightly. because the higher samarium concentrations in the aqueous phase allow less cerium and neodymium to be extracted into the organic phase.

The above characteristics were part of the reason why oniy one control variable was needed. In addition, the 
control requirements were that both output variables be maintained at values greater than the 99 percent. level and. not at specified set points. If the control requirements had been the latter, it would have been impossible to control the extractor with just one control variabie. This control scheme of using one control variable to control both output variables can probably be applied to other extraction systems. Similar output variable characteristics have been noticed in results from the steady state analysis of an actual extractor. Casto's $(6,7)$ steady state analysis of a rare-earth extractor showed that for a feed flow rate decrease that extract purity fell but that raffinate purity rose. Just the opposite effects were observed for a feed flow rate increase. In doing extractor control studies characteristics such as these should be looked for to simplify the control scheme. The effect on the output variables of a change in the control variable was also important to the control study. If samarium feed concentration and feed flow rate were maintained at their desired operating values and if solvent. flow rate, E, was decreased then samarium recovery fell and extract purity rose. If $\mathrm{E}$ was increased the opposite effects were noted. Therefore, if a measured input variable change occurred that lowered samarium recovery then solvent flow rate was increased to control the upset. If solvent 
flow rate had been decreased both it and the upset would have had the effect of lowering samarium recovery. In a similar manner if an upset occurred that lowered extract purity then solvent flow rate was decreased.

One other point must be mentioned concerning extraction characteristics. Equation 14 shows that the predictive control steady state gain equation is a function of the samarium feed concentration, $\mathrm{x}_{\mathrm{Sm}^{\prime}}^{\mathrm{f}}$ and not the feed concentrations of either cerium or neodymium. The reason for this was that changes in the latter feed concentration terms had a very smali effect on extract purity and samarium recovery. This is because most of the cerium and neodymium remain in the aqueous phase as they pass through the extractor. To simplify the steady state gain equation the cerium and neodymium feed concentrations were not Included. 
CONTROL STRATEGY

The control diagram.for the predictive control of the mixer-settler extractor is presented in Figure 4 . The extractor variables monitored by the computer are the feed. and solvent flow rates and the compositions of the feed, extract and raffinate streams. The computer program input variables are feed flow rate, $F$, solvent flow rate $E_{s}$ ' samarium feed concentration, $x_{S m^{\prime}}^{f}$ extract purity, $x_{p^{\prime}}$ and the purity of the combined rare-earths cerium and neodymium in the raffinate, $R_{p}$. Extract purity and raffinate purity are calculated by the computer from the compositions of the extract and raffinate streams.

The variables $X_{p}$ and $R_{p}$ were needed for the feedback trimmer portion of the predictive control scheme. Extract purity was one of the output variables being controlled, but the other output variable was samarium recovery, Re, and not raffinate purity, $R_{p}$. The reason raffinate purity was used instead of recovery was because recovery is calculated from the steady state material balance and thus it cannot be calculated accurately during a transient period when the unsteady state material balance applied. Raffinate purity was therefore used as an estimate of recovery. This worked quite well since raffinate purity was directly a measure of the amount of samarium being lost.

Because of the nature of the variables monitored by 


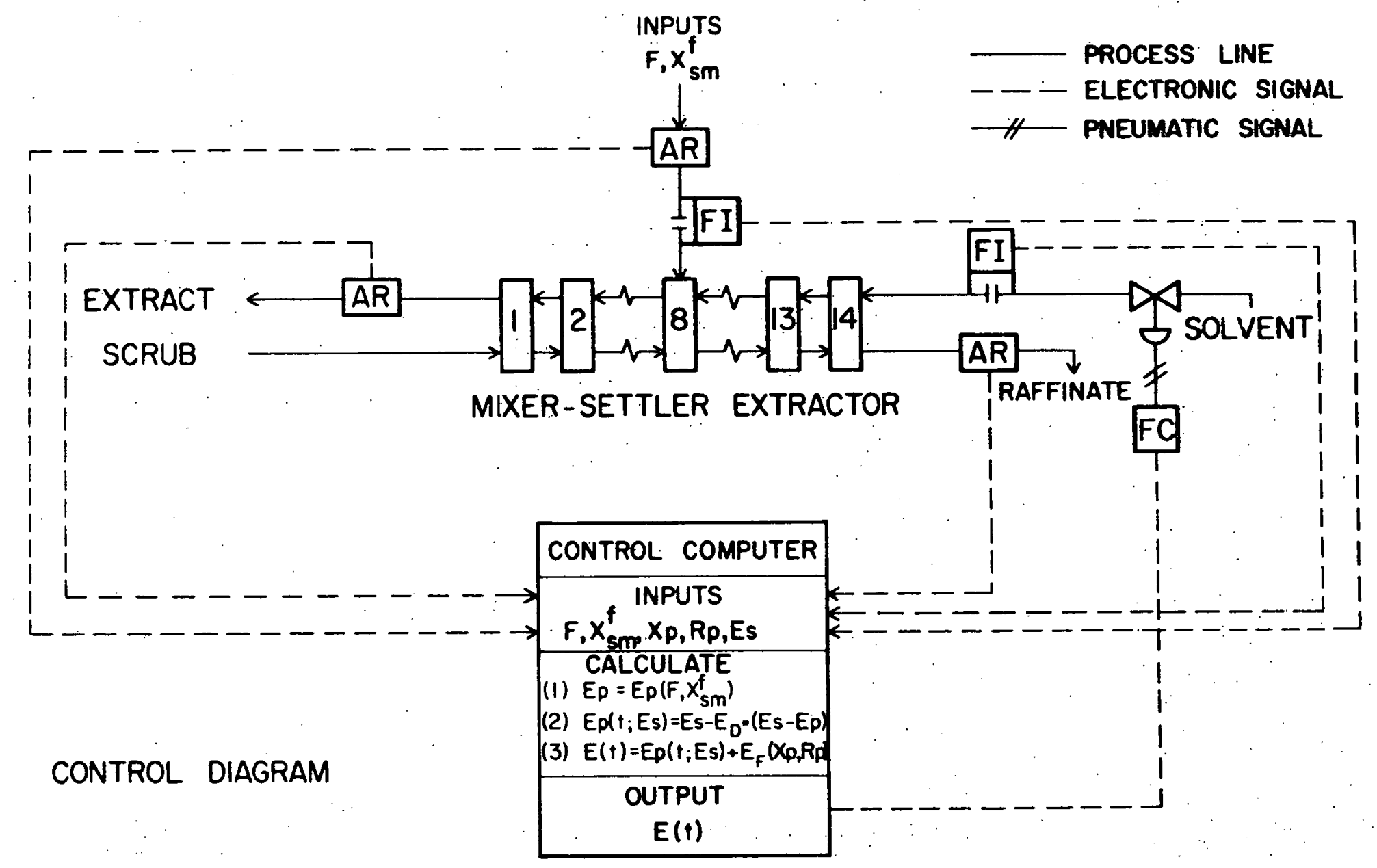

Figure 4. Control diagram for the predictive control of the mixer-settler extractor 
the computer, it is impossible with a real extractor to continuously monitor these variables. Flow rate information is continuously available but the compositions of the various streams are not because of the time factor involved in the on-line chemical instrumental analysis. Therefore the control computer would be programmed to scan the extractor variables at a set time interval.

When the computer scans the measured input variables it must check to see if their values have changed during the interval between scanning times. If the input variables have changed the predictive control scheme is reinitiated because each new measured input variable setting requires a new predicted value for the control variable. As long as the measured input variables remain constant the control variable setting only changes due to feedback trimmer action. When the predictive control scheme is initiated the first step is the calculation of the steady state gain term, $E_{p}$ using Equation 14. This value is then used in the dynamic predictive control equation, Equation 17, which gives the change in $E_{p}$ as a function of time, $E_{p}\left(t ; E_{s}\right)$. This predicted value for the solvent flow rate is then combined in the predictive control equation, Equation 19, with a feedback trimmer to give the controller setting for the solvent flow rate as a function of time.

The integral portion of the feedback trimmer was reset 
to zero each time the predictive control scheme is initiated. When the measured input variables are at their desired operating values the feedback trimmer can act as a closed loop feedback controller to handle any deviations in the output variables which might occur because of unmeasured input variable changes.

It was necessary to determine which output variable decreases for a particular upset. This variable was then used in the feedback trimmer calculation. The method used to determine the correct output variable is based on a comparison of the set point value for solvent flow rate, $\mathrm{E}_{\mathrm{Sp}}$, to the predicted value for solvent flow rate, $\mathrm{E}_{\mathrm{p}}$, calculated for the upset. The steady state gain equation for $E_{p}$ is such that if both samarium feed concentration, $\mathrm{x}_{\mathrm{Sm}}$ ' and feed flow rate, $F$, are at their desired operating values the calculated value of $\mathrm{E}_{\mathrm{p}}$ will equal $\mathrm{E}_{\mathrm{sp}}$. It is known from the analysis of the system that if an upset occurs that effects extract purity (a decrease in either $x_{S m}^{f}$ of F), $E_{p}$ is calculated to be less than $E_{s p}$. Therefore, when $\mathrm{E}_{\mathrm{p}}$ is less than $\mathrm{E}_{\mathrm{sp}}$ extract purity is used as the trimmer variable and when $\mathrm{E}_{\mathrm{p}}$ is greater than $\mathrm{E}_{\mathrm{sp}}$ raffinate purity is used as the trimmer variable.

The same procedure was used to determine which output variable to use as the trimmer variable in the case where 
one measured input variable is greater than its desired operating value and the other less than its desired operating value. Simultaneous upsets of this form tend to cancel each other out. One upset causes more samarium to enter the extractor and the other causes less. Since... $\mathrm{E}_{\mathrm{p}}$ is a measure of the effect of the individual upsets, it is also a measure of the effect of the combined upsets. Thus, as before, the calculated value of $\mathrm{E}_{\mathrm{p}}$ is used to determine which output variable to use with the feedback trimmer. 


\section{RESULTS AND DISCUSSION}

\section{Extractor Simulation}

In this study the unsteady state extractor simulation was used as a method of determining steady state operating conditions, as a means of studying the response characteristics of the extractor, and as a stand-in for the real extractor in the control studies.

The simulation was used in the extractor design phase to calculate steady state conditions. The number of stages, feed conditions, and the acid and solvent concentrations were set and the solvent and scrub flow rates were varied until output variable specifications were met. The desired operating conditions determined were presented in a previous section. Although these conditions were not optimum, for this was not the purpose of the work, they were in the range expected for such an extractor. The use of 14 stages was in line with the experimental work of Casto $(6,7)$ who studied the separation of rare-earths using both 10 and 20 stage, laboratory scale, mixer-settler extractors. The solvent to feed ratio in terms of moles of D2EHPA per mole of rare-earth chloride, determined from the simulation was 6.2/1 and for Casto's experimental study it was in the range of $6 / 1$. Thus the extractor design is one that corresponds to existing extractors.

Using the simulation to determine steady state 
conditions was also done in the calculation of data for the predictive control steady state gain equation. It was used to calculate the values of the output variables corresponding to different combinations of the measured input and control variables.

The calculation of dynamic responses to input variable upsets is the common usage for this type of simulation. In this study responses to measured input and control variable changes were obtained and used in the determination of the dynamic compensation term, $E_{D}(t)$, for the predictive control model. It was not possible to compare the calculated responses to actual responses from an extractor separating the rare-earth mixture used in this study. However, it was possible to compare the calculated response to experimental responses from an actual extractor separating a different rare-earth mixture under similar conditions. Casto (6) studied the dynamic characteristics of a 10 stage mixersettler extractor and his experimental response to feed flow rate upsets is shown in Figure 5. The simulated response to similar upsets is shown in Figure 6. The response characteristics are similar thus indicating that the simulation is giving realistlc responses.

For the control studies the simulation was used as a stand-infor the real extractor. A measured input variable was changed and the simulation allowed to respond while 
Figure 5. Experimental response to changes in feed flow rate

Steady state Flow Rate $3.69 \mathrm{ml} / \mathrm{min}$

Step Changes In Feed Flow Rate

Time (min) Feed Flow Rate (mi/min)

$$
\begin{array}{ll}
145 & 7.71^{\star} \\
309 & 0.0
\end{array}
$$

${ }^{*}$ Flow rates held 10 minutes

Figure 6. Simulated response to changes in feed flow rate

Steady State Flow Rate 5.0 liters $/ \mathrm{min}$

Step Changes In Feed Flow Rate

Time (min) Feed. Flow Rate (liters $/ \mathrm{min}$ ) $500 \quad 4: 0$

*Flow rates held 50 minutes 

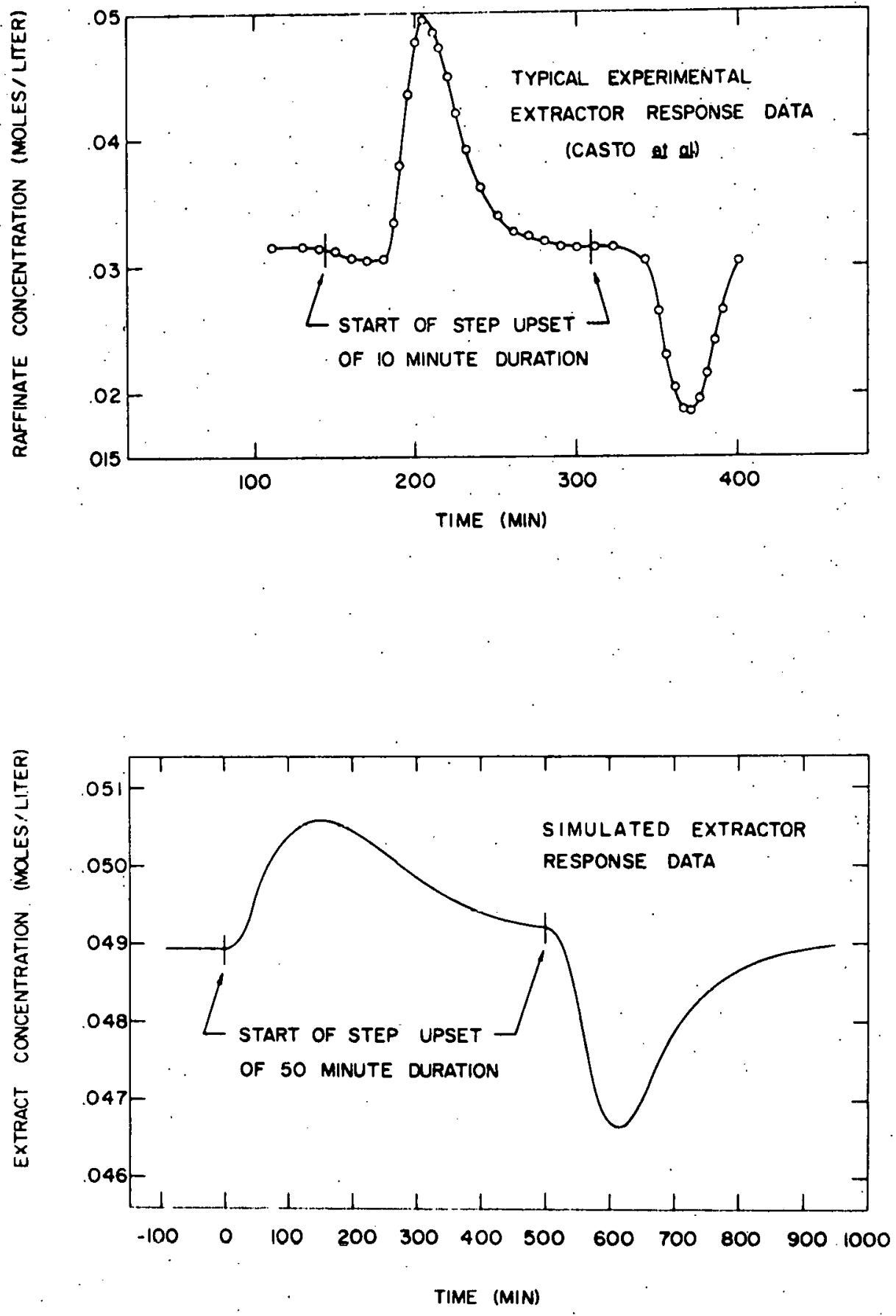
being monitored and controlled by the control program. The output variable responses are presented below in the discussion of predictive control.

Solvent Flow Rate Predictive Control:

The equation for the steady state gain term of the predictive control model is,

$$
E_{p}=a_{1} x_{S m}^{f}+a_{2} F+a_{3} x_{p}+a_{4} R e+a_{5}
$$

The values for the regression coefficients, $a_{i}$, are found in Table 1. The calculated value for $a_{5}$ from the linear regression analysis is shown in parenthesis in Table 1. A corrected value for $a_{5}$ is used in Equation 20, as mentioned in the control strategy, so that the calculated value for solvent flow, $E_{p}$. equals the desired set point value for solvent flow rate, $E_{s p}$. Equation 20 would be the predictive control equation if dynamic compensation were not used. Control responses based upon this equation will be called steady state gain predictive control responses.

The dynamic compensation transfer functions were determined from dynamic responses to step changes in the measured input and control variables. All dynamic and control responses presented in this section are for step upsets unless mentioned otherwise. The open loop responses for samarium feed concentration 
Table 1. Regression coefficients for E flow rate linear regression equation

\begin{tabular}{ccc}
\hline & \multicolumn{1}{c}{$a_{i}$} \\
\hline 1 & 73.8020 & \\
\hline 2 & 5.5609 & \\
3 & -100.1670 \\
4 & 42.3115 \\
5 & $40.1155 \quad(40.026)$ \\
$\sqrt{r^{2}}$ & 0.97523 & \\
\hline
\end{tabular}

decreases, feed flow rate decreases, and solvent flow rate decreases are presented in Figures 7,8 , and 9 respectively. As will be explained later, the responses for increases in these variables were not needed. The ordinate for the response curves is percent response-extract purity. The first step in the dynamic compensation procedure was to obtain approximating transfer functions for the responses. Because of the S-shaped nature of the measured input variable responses higher order transfer functions were needed to approximate the responses. A trial and error procedure was used to determine the transfer functions time constants. The procedure consisted of first inverting the transfer function into the time domain assuming a step upset 


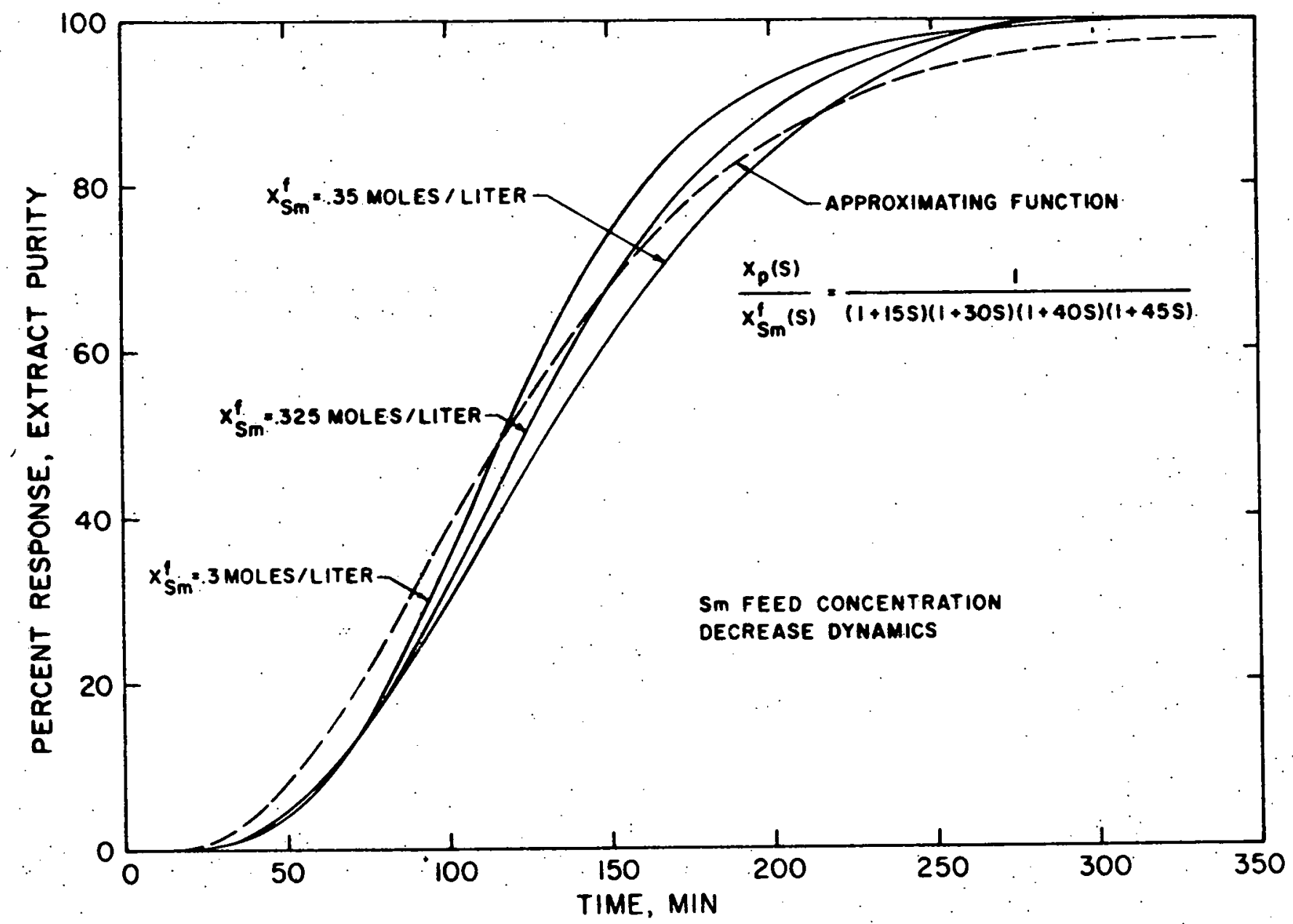

Figure 7. Comparison of the actual responses and the approximating response for samarium feed concentration decrease upsets 


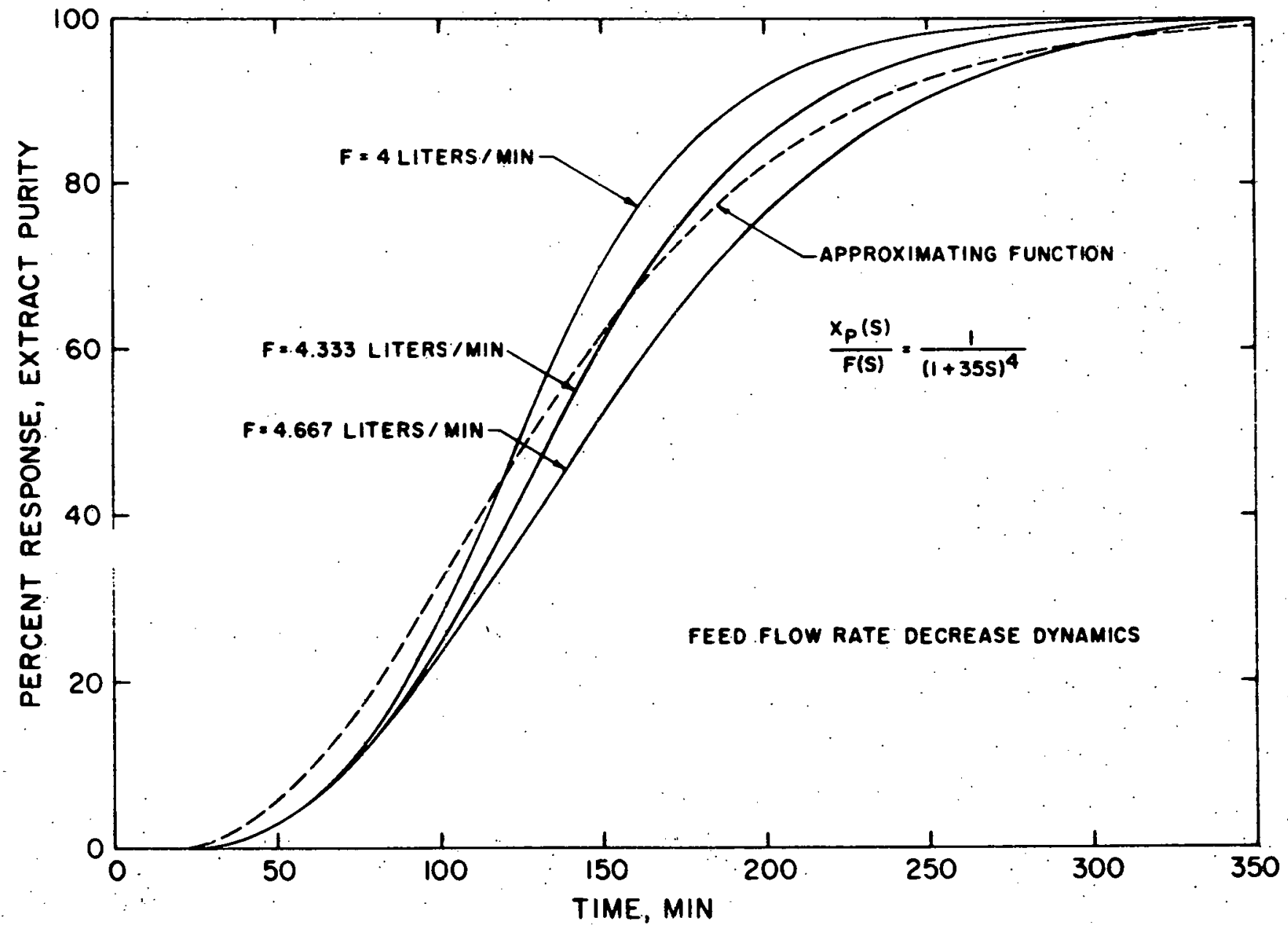

Figure 8. Comparison of the actual responses and the approximating response for feed flow rate decrease upsets 


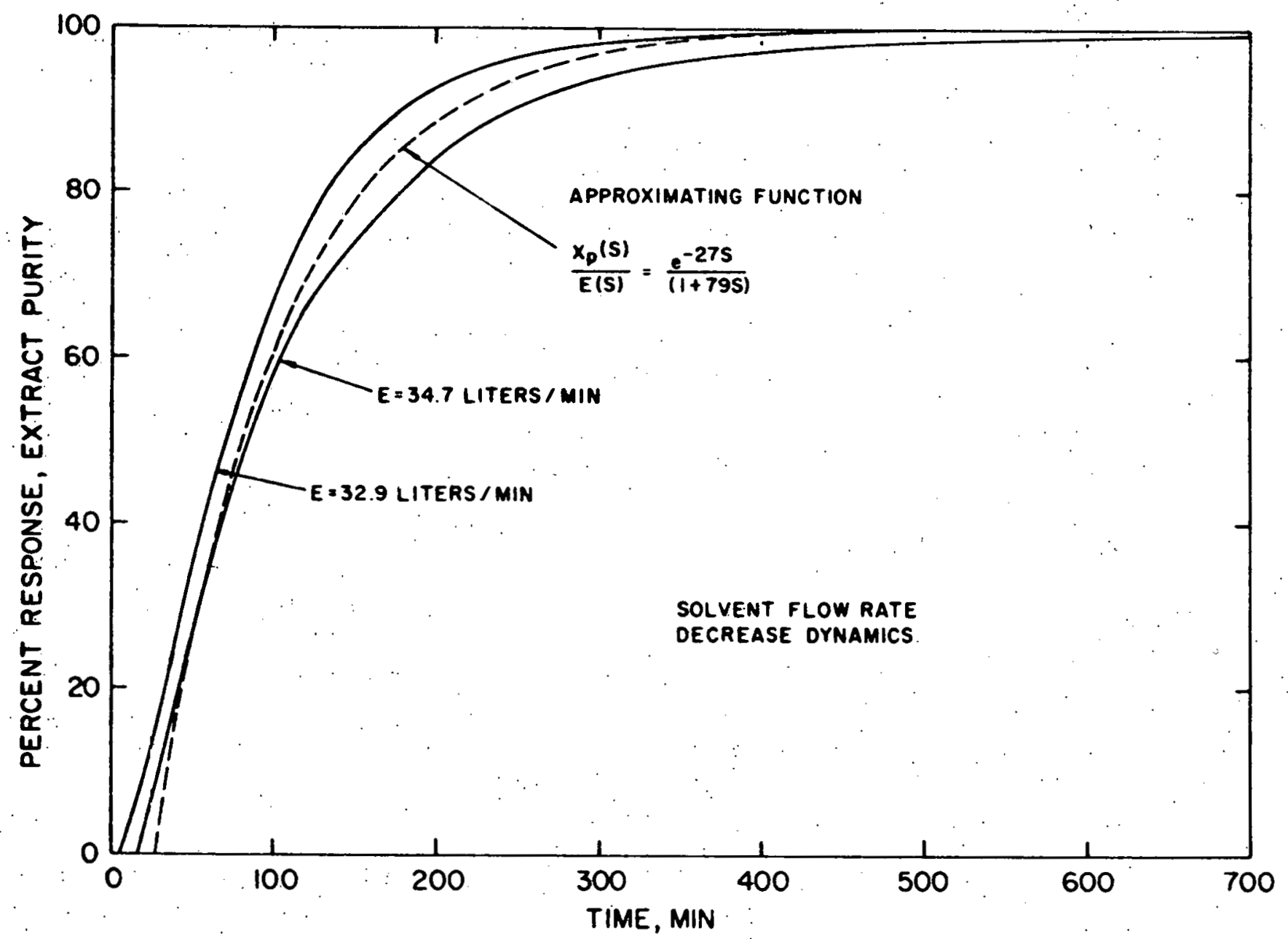

Figure 9. Comparison of the actual responses and the approximating response for solvent flow rate decrease upsets. 
for the measured input variable. This gave an expression for extract purity, $x_{p}$, as a function of the time constants and time. The time constants were then varied until the $x_{p}$ response approximated the actual response curves.

The approximating transfer functions for the measured input variable upsets were,

Samarium Feed Concentration Upset:

$$
\frac{x_{p}(s)}{x_{S m}^{f}(s)} \cong \frac{1}{(1+15 s)(1+30 s)(1+40 s)(1+45 s)}
$$

Feed Flow Rate Upset:

$$
\frac{X_{p}(s)}{F(s)} \cong \frac{1}{(1+35 s)^{4}}
$$

The curves corresponding to these transfer functions are shown as dashed lines in the figures. It appears that these approximating functions do not fit the responses as well as they possibly could. However, the problem encountered with both of these approximating functions was that when they were made to fit well at small times they fit poorly at large times and when they fit well at large times they fit poorly at small times. The transfer functions chosen were those that tended to minimize the deviations at the ends.

The procedure used for determining the approximating transfer function for the solvent flow rate, E, responses was somewhat simpler. These curves, shown in Figure 9, 
resemble first order responses with initial dead times. The method used to determine the time constant and dead time for the approximating transfer function was based on the fact that for a first order response the dependent variable reaches 63.2 percent of its final value in one time constant and 86.5 percent of it in two time constants. With this information two simultaneous equations were written and solved to give the desired constants.. The approximating transfer function was determined to be,

$$
\frac{X_{p}(s)}{E(s)} \cong \frac{e^{-27 s}}{1+79 s}
$$

This approximating function fit well at large times but the calculated dead time was about twice as large as it appeared it should be. However, compared to the overall time of the response the deviation in the dead times was small.

The dynamic compensation terms relating the control variable to the measured input variables were determined by dividing Equations $21 \mathrm{a}$ and $21 \mathrm{~b}$ by Equation 22 giving,

Samarium Feed Concentration Upset:

$$
\frac{E(s)}{x_{S m}^{f}(s)} \cong \frac{e^{27 s}(1+79 s)}{(1+15 s)(1+30 s)(1+40 s)(1+45 s)}
$$


Feed Flow Rate Upset:

$$
\frac{E(s)}{F(s)} \cong \frac{e^{27 s}(1+79 s)}{(1+35 s)^{4}}
$$

These expressions were inverted into the time domain, assuming step upsets for the measured input variables, to obtain the dynamic terms, $E_{D}(t)$, used in Equation 17, the dynamic predictive control equation. The positive sign of the exponential coefficient in the transfer functions indicates that the response of $E_{D}(t)$ must lead the measured input variable response by 27 minutes. Therefore, the time variable used in the equations for the dynamic terms, $E_{D}(t)$, must be $t+27$, where $t$ is the time measured from the start of the measured input variable upset.

The dynamic term, $E_{D}(t)$, obtained from Equation $22 a$ was used in the dynamic predictive control equation to obtain the controlled response for a 20 percent samarium feed concentration decrease. This response is shown as the lower curve in Figure 10.' The calculated response for solvent flow rate, $E_{p}\left(t_{i} E_{s}\right)$, from Equation 17 is the upper curve in Figure 11. Control was not very good because it allowed the extract purity response to drop below the 99 percent level. The response was not even as good as the steady state gain predictive control response for the same upset which is shown in Figure 12. Dynamic compensation 


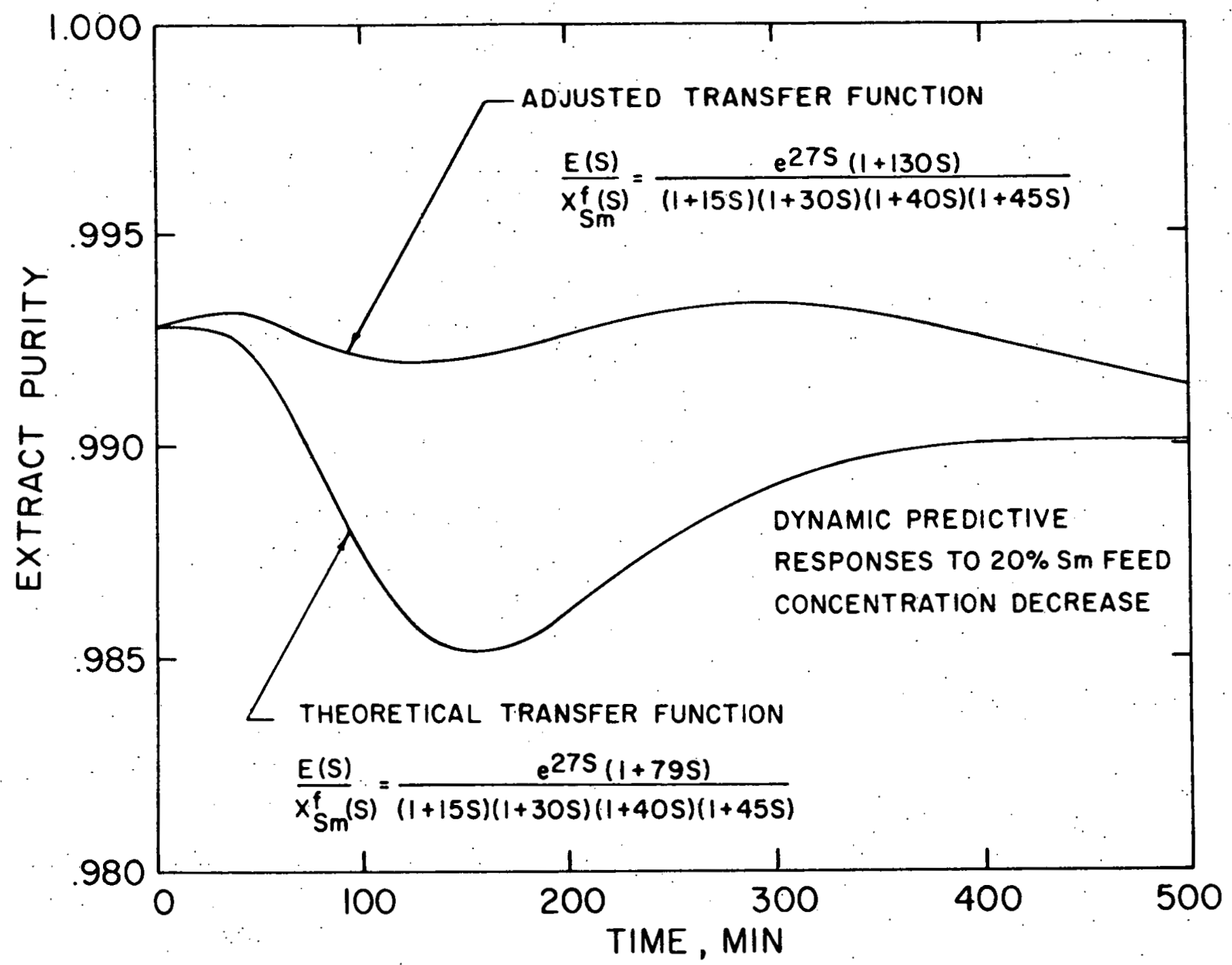

Figure 10. Comparison of dynamic predictive control responses for the theoretical and adjusted transfer functions 


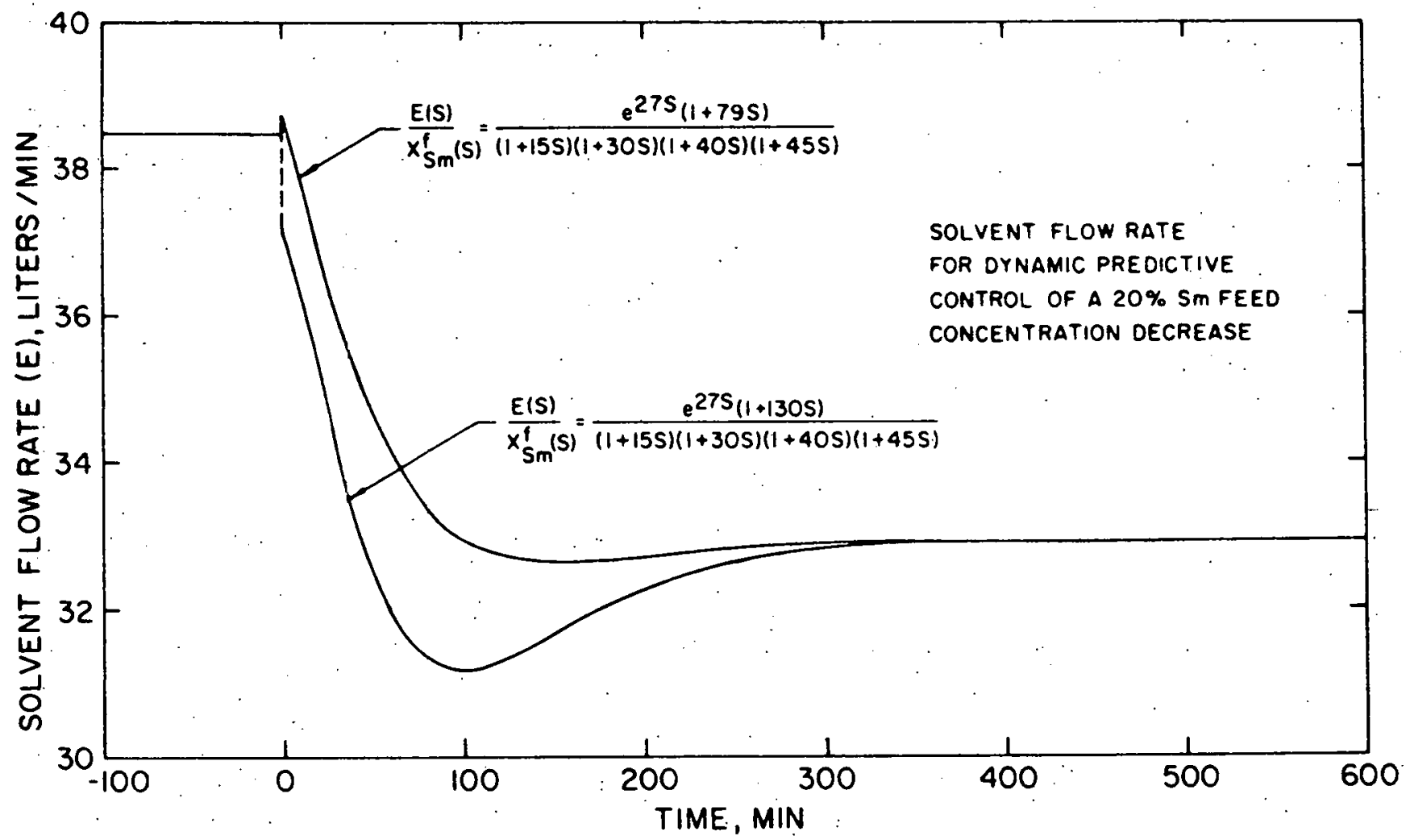

Figure 11. Comparison of solvent flow rate responses for the theoretical and adjusted transfer functions 
had not improved the control at all.

A clue to the reason for the failure of the dynamic compensation can be seen in the solvent flow rate response in Figure 11. At the start of the upset the initial change in solvent flow rate was an increase followed by an exponential decrease. This initial increase in solvent flow rate was causing the poor response. To eliminate the solvent flow rate increase, the time constant in the numerator of Equation 23a was increased to give a smaller lag.

Various values for the time constant were tried and a final value of 130 was chosen because the extract purity response corresponding to the adjusted transfer function oscillated about the extract purity set point before dropping to the final steady state value. This response is shown as the upper curve in Figure 10. With this new value the solvent flow rate response in. Figure 11 no longer exhibited an initial increase.

The dynamic compensation term, $E_{D}(t)$, based on the adjusted transfer function was,

$$
\begin{aligned}
E_{D}(t)= & 1-2.3 e^{-(t+27) / 15}+40.0 e^{-(t+27) / 30} \\
& -115.2 e^{-(t+27) / 40}+76.5 e^{-(t+27) / 45} .
\end{aligned}
$$

The question arises as to why the original compensation transfer function did not give a better extract purity 
response. It was probably because the transfer function was a combination of two transfer functions which were both approximations to a family of responses.

Using dynamic compensation a predictive control response was calculated, from Equation 19, and compared to a dynamic predictive control response and a steady state gain predictive control response. This comparison is presented in Figure 12 for the 20 percent samarium feed concentration decrease. The predictive response, because of the feedback trimmer, has eliminated the final offset of the dynamic predictive response. Comparing the dynamic predictive response to the steady state gain predictive response shows that dynamic compensation was helpful in improving the control. However, the latter response is not bad, and if a feedback trimmer were used with the steady state gain equation the response would be acceptable in terms of the control requirements.

The final comparisons for the samarium feed concentration upset are shown in Figure 13. This figure shows the advantage of predictive control over feedback control and compares both controlled responses to the uncontrolled response. The predictive control response deviates only slightly from the extract purity set point but the feedback control allows extract purity to drop below the 99 percent level. 


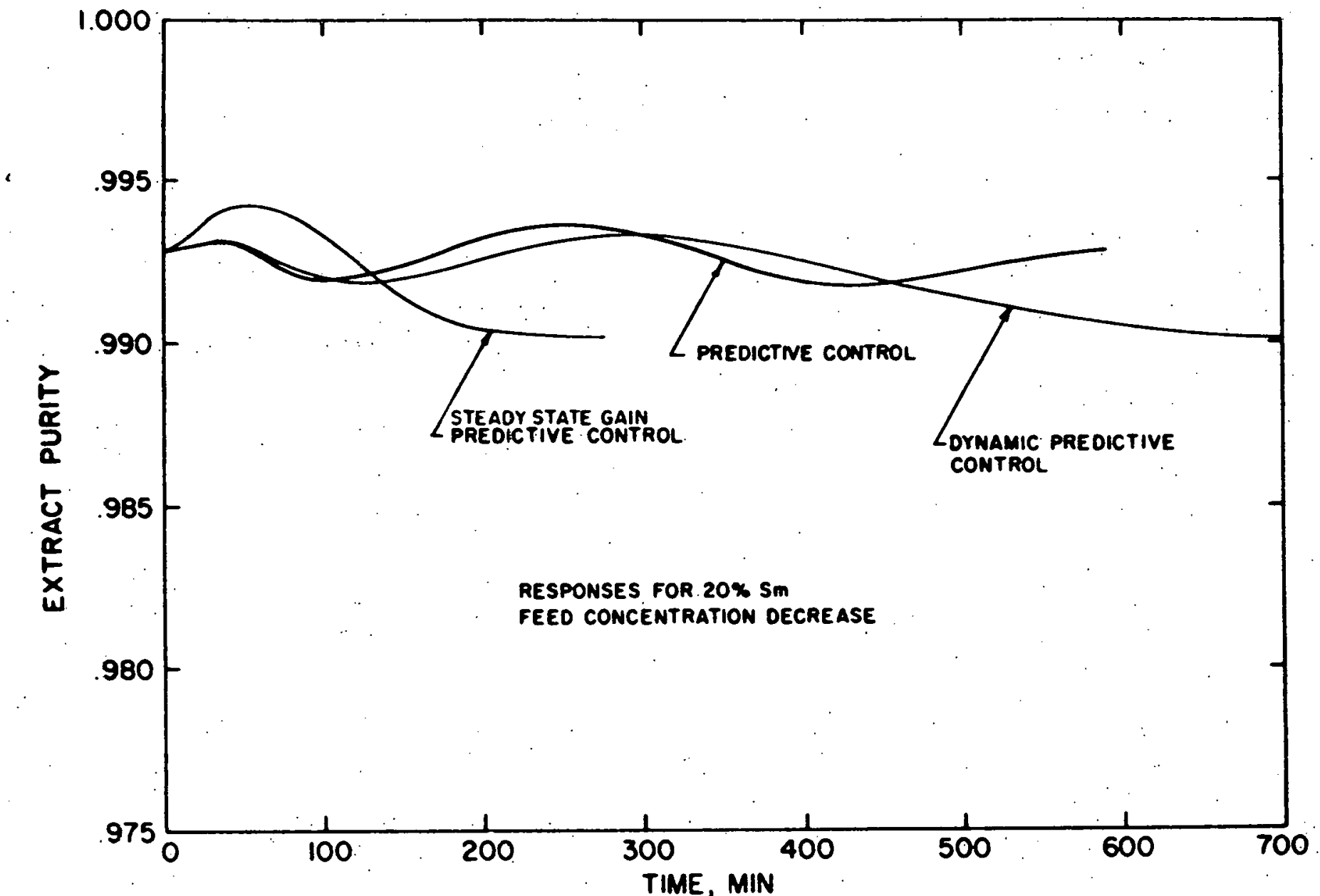

Figure 12. Comparison of the three different forms of predictive control 


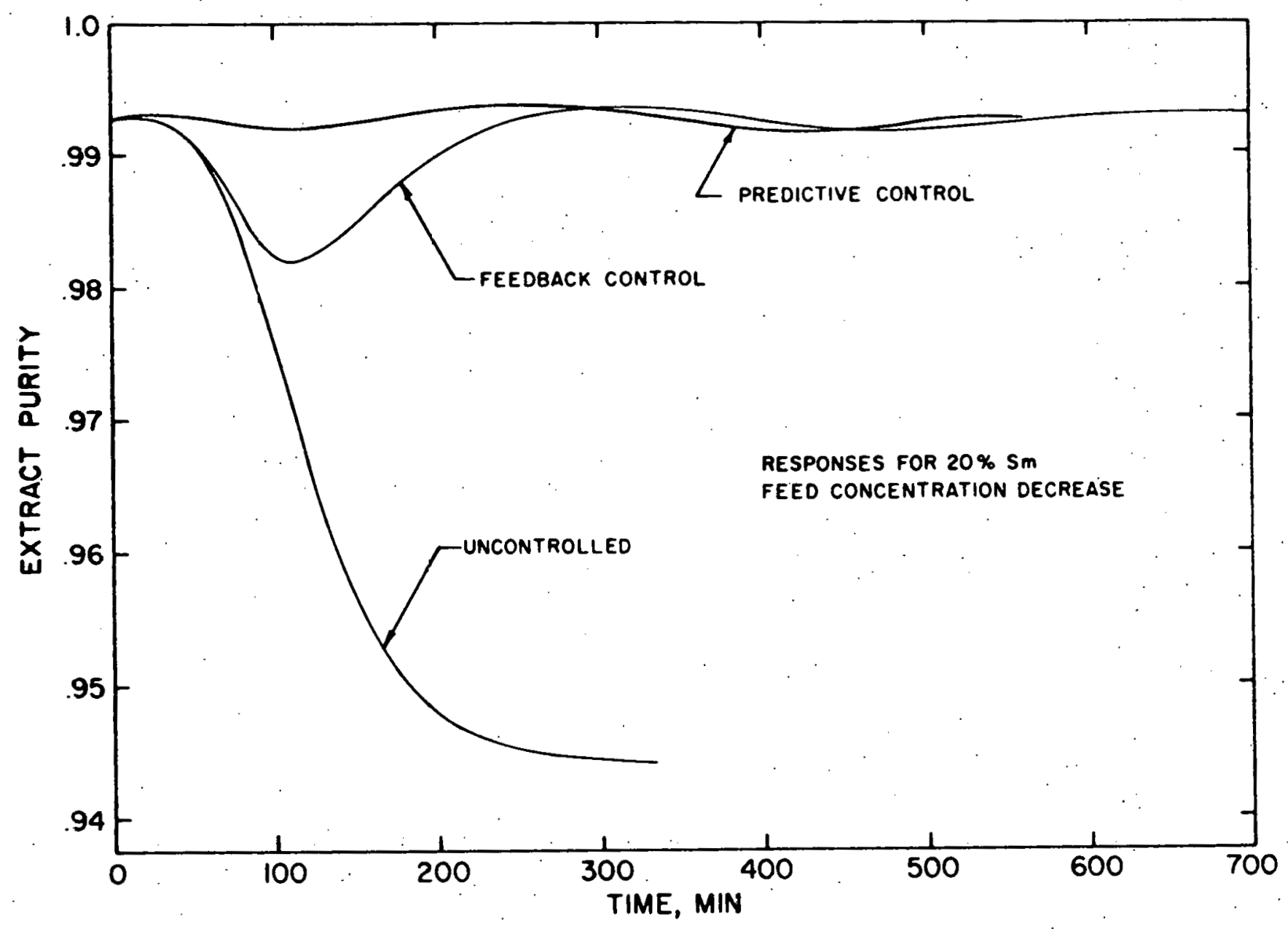

Figure 13. Responses showing the advantage of predictive control over feedback control and the uncontrolled response for a 20 percent samarium feed concentration decrease 
The problem encountered with the dynamic compensation transfer function for a samarium feed concentration decrease was also encountered for a feed flow rate decrease. The transfer function, Equation 23b, was modified in the same way by changing the value of the numerator time constant to 130. This modification improved the dynamic predictive control response for the feed flow rate decrease as it did for a samarium feed concentration decrease. The modified dynamic compensation transfer function gave the following expression for the dynamic compensation terms, $E_{D}(t)$,

$$
\begin{gathered}
E_{D}(t)=1-e^{-(t+27) / 35}\left[1+\frac{t+27}{35}+\frac{1}{2}\left(\frac{t+27}{35}\right)^{2}\right. \\
\left.\quad+\frac{1}{6}\left(\frac{t+27}{35}\right)^{3}\right]+130 \frac{e^{(t+27) / 35 \cdot(t+27)^{3}}}{6 \cdot 35^{4}} .
\end{gathered}
$$

The predictive control curve for a feed flow rate decrease is shown in Figure 14, as well as those for feedback control and for no control. Again the predictive control response is much better than that for only feedback control. As mentioned earlier no dynamic compensation transfer functions were determined for either samarium feed concentration or feed flow rate increase upsets. They were not used because steady state gain predictive control, and even feedback control, gave good control of either upset. A steady state gain predictive control response to a 20 percent 


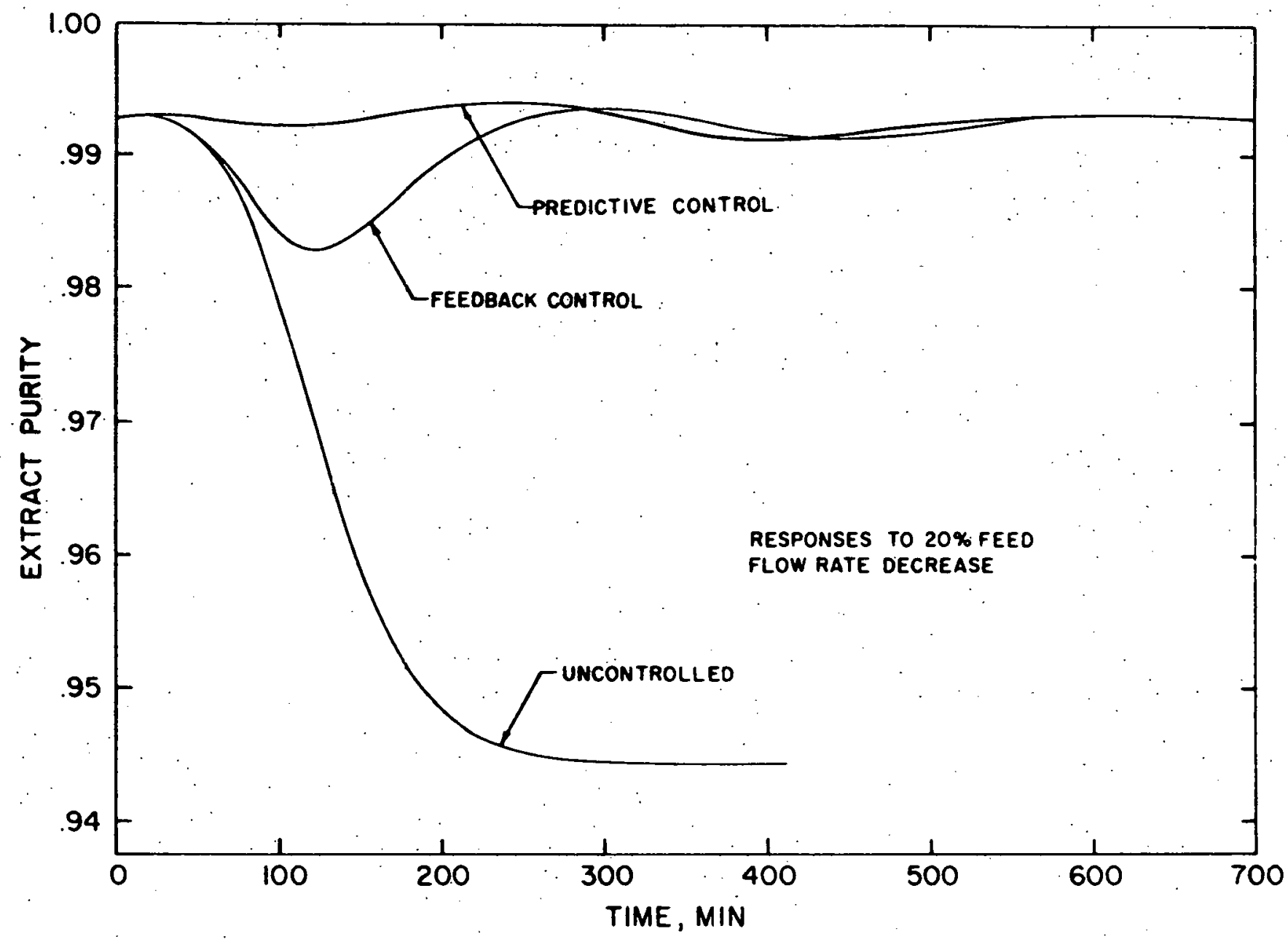

Figure 14. Responses showing the advantage of predictive control over feedback control and the uncontrolled response for a 20 percent feed flow rate decrease 
samarium feed concentration increase is shown in Figure 15. The feedback response was not included because it was so close to the predictive response. The same types of curves were obtained for a feed flow rate increase.

The reason for the good control without dynamic compensation can be inferred by comparing the uncontrolled response for the samarium feed concentration decrease presented in Figure 13 and the uncontrolled response for the samarium feed concentration increase presented in Figure 15. For a concentration increase the response is more delayed. That is, its initial rate of decay is much slower than that for the concentration decrease. Therefore, the controller has more time to respond: to the increase upset and thus gives better control.

The results presented have shown that predictive control is an excellent method of controlling the extractor. They have shown that dynamic compensation is useful in improving the predictive control responses. The results have also shown that steady state gain predictive control is not a. bad means of control, especially for the measured input variable increases. Therefore, in applying predictive control to chemical processes, one should first check to see if steady state gain control is able to give satisfactory control before applying any dynamic compensation. The upsets discussed to this point have been single 


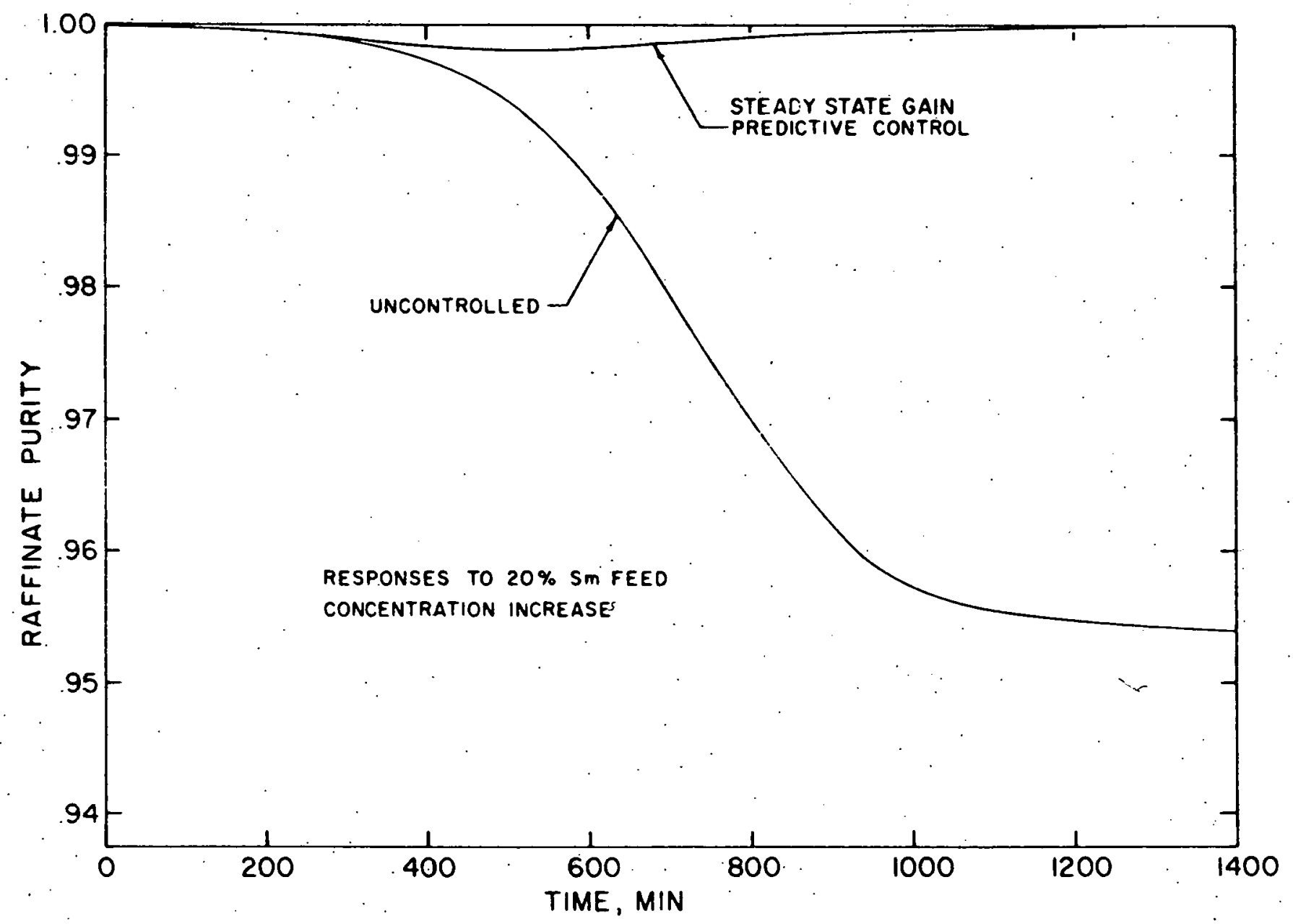

Figure 15. Steady state gain predictive control response and the uncontrolled response for 20 percent samarium feed concentration increase 
step changes of a measured input variable. What would happen if there were a sequence of changes in the measured in- put variables? At present it would depend on the type of upset as to which dynamic compensation term would be used, if any. Also, if there were a simultaneous decrease in both samarium feed concentration and feed flow rate, how would the corresponding dynamic compensation terms be combined to give the correct resulting compensation?

These problems were resolved by using one dynamic compensation. transfer function for all measured input variable upsets. The transfer function chosen was the one for a samarium feed concentration, $\mathrm{x}_{\mathrm{Sm}}^{\mathrm{f}}$, decrease. The reason for this choice can be inferred from Figure 16. This figure shows dynamic predictive control responses for a samarium feed concentration upset using the F dynamic compensator, Equation 25 , and a feed flow rate upset using the $x_{S m}^{f}$ dynamic compensator, Equation 24. The $x_{\text {Sm }}^{f}$ dynamic compensator controlled the feed flow rate upset better than the $F$ dynamic compensator controlled the samarium feed concentration upset. For this reason the $\mathrm{x}_{\mathrm{Sm}}^{\mathrm{f}}$ compensator was chosen to be used for all upsets.

The final curve, presented in Figure 17, is the controlled response for a time varying samarium feed concentraction upset, also shown in the figure, using the $\mathrm{x}_{\mathrm{Sm}}^{f}$ dynamic compensator and the control scheme outlined in the 


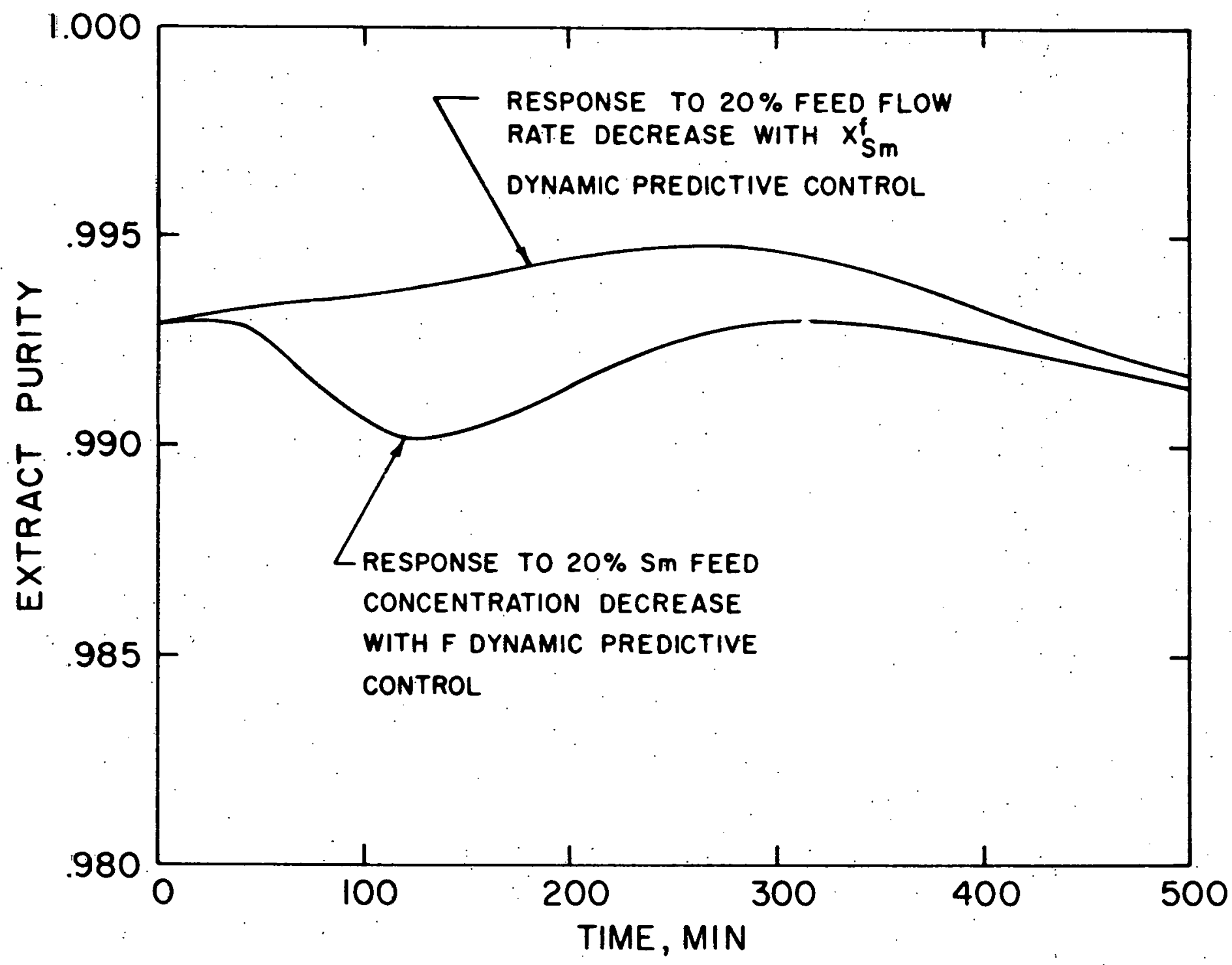

Figure 16. Comparison of two different dynamic predictive control functions 


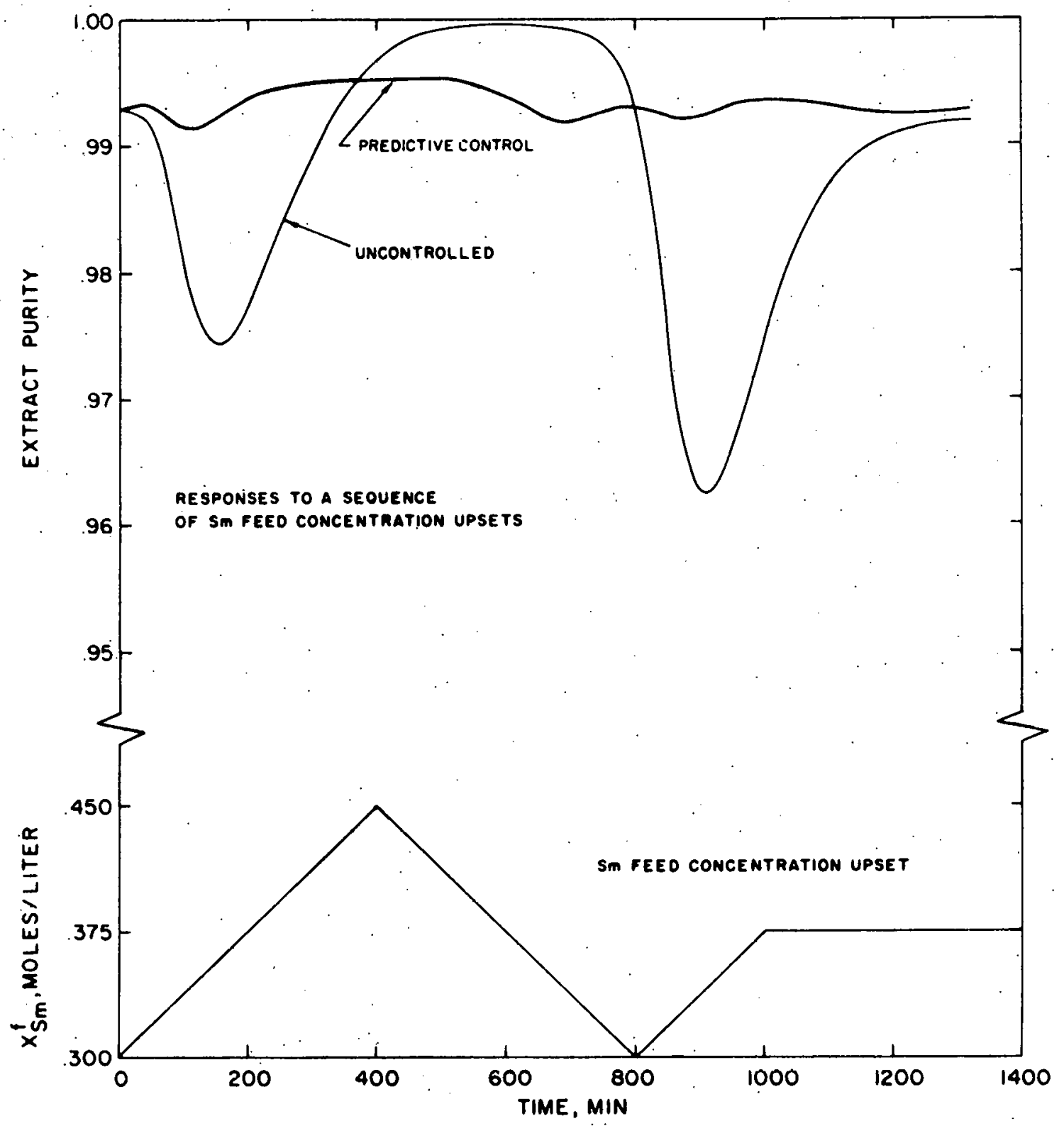

Figure 17. Responses to a time varying samarium feed concentration upset 
control strategy section. The control program monitored the input variables every 5 minutes. The figure shows that the control of extract purity was very good. The raffinate purity response was not included because it deviated only slightly from its desired set point.

The predictive control model determined in this study has been shown to work well for controlling the mixersettler extractor. The model is simple enough in terms of the calculations involved that the control scheme could be implemented with a small control computer. The additional capital costs involved, over those for feedback control equipment, would be for the control computer and the composition analyzer on the feed stream. If the specifications on product purity and product recovery were very important this would not be too high a cost to pay for the improved operation of the extractor.

The method used to obtain the predictive control model worked well. It has the advantage that it can be used for procesșes described by nonlinear, time varying, differential equations as was this extractor. None of the analytical predictive control procedures could be used with this simulation. This method is one that should see more use as the process simulations become more exact and complicated. 
Other Predictive Control Variables

Before solvent flow rate was chosen, as the control variable, the flow ratio $a(=S / E)$ was used. Although $a$ predictive control was a satisfactory means of control, it was abandoned in favor of solvent flow rate, : $\mathrm{E}$, predictive control because of the responses shown in Figure 18. With a control both solvent and scrub flow rates changed to facilitate control. However, it was determined that the scrub flow rate, $s$, change associated with $\alpha$ control could not be used alone to control the upset, as is shown in the figure, and that this change in $S$ was hindering the a control.

one effect that changing the scrub flow rate had on $\alpha$ control was found by comparing the flow rates corresponding to the responses in Figure 18. For the upset used in this comparison the change in the solvent flow rate for a control was over two liters/min greater than the change for $\mathrm{E}$ control; the desired operating value for solvent flow rate being 38.46 liter/min. This additional change in solvent flow rate for a control was needed to counteract the change in the scrub flow rate. Another advantage of $E$ predictive control is that its response comes to steady state more rapidly than does the $\alpha$ response. This slowness of response on the part of a control was due again to the scrub flow rate change. 


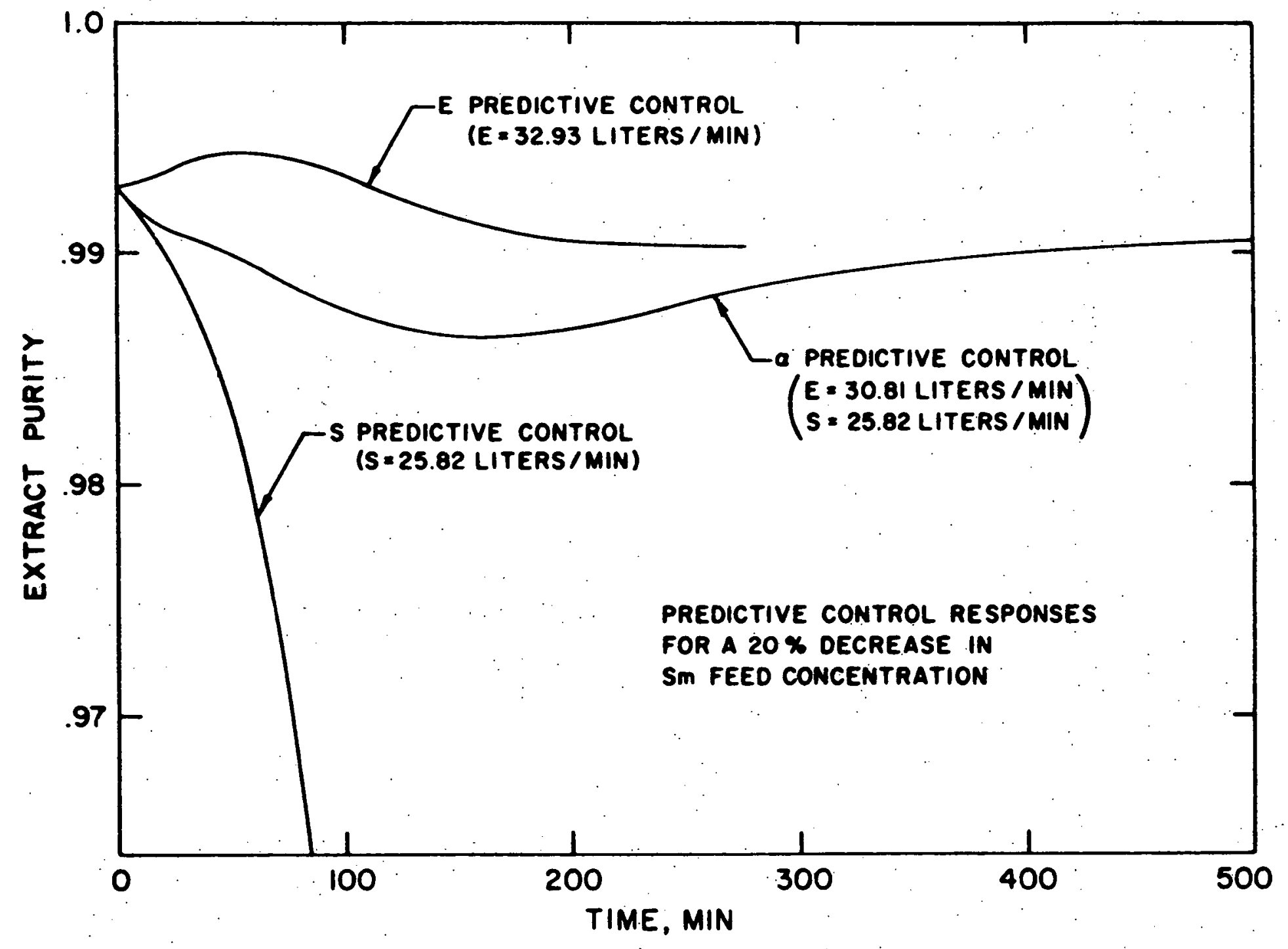

Figure 18. Comparison of $\mathrm{E}, \mathrm{S}$ and $\alpha$ predictive control 


\section{CONCLUSIONS}

1. The numerical integration method used in solving the unsteady state equations for the extractor gave dynamic responses similar to those obtained experimentally by other investigators. The iteration between the distribution coefficlent and the aqueous phase rare-earth concentration converged without difficulty and the use of first order lags in the flow stream was a useful approximation to the physical response of those streams in a mixer-settler extractor.

2. Predictive control was a more effective means of controlling the mixer-settler extractor than was feedback control. The use of solvent flow rate as the control variable provided good regulation of the process.

3. Because of the output variable characteristics of the extractor and the control specifications placed on the output variables, it was possible to control both output variables with one control variable. Characteristics of this type are sure to exist in other extractions and should be considered in carrying out a control study.

4. The prealcive cuntrol of the extractor using only a steady state gain model gave responses which met output variable specifications. However, the addition of dynamic compensation improved the predictive control 
responses.

5. The complexity of the calculations associated with the predictive control scheme are such that they could be implemented with a smali control computer.

6. The procedure used for obtaining the predictive control model works well for processes described by nonlinear, time varying, differential equations. It is a method that should be considered in doing any predictive control work. 


\section{LITERATURE CITED}

1. Bollinger, R. E. and Lamb, D. E. Multivariable systems-analysis and feedforward control synthesis. Industrial and Engineering Chemistry Fundamentals 1 : 245-252. 1962 .

2. Bollinger, R. E. and Lamb. D. E. The design of a combined feedforward-feedback control system. Process Engineering Progress Symposium Series: Process Control and Applied Mathematics 55: 66-77. . 1965.

3. Cadman, T. W. and Hsu, C. K. Dynamics and control of multi-stage liquid extraction. Transactions of the Institution of Chemical Engineers 48: T209-T226. 1970.

4. Callow, R. J. The industrial chemistry of the lanthanons, yttrium, thorium and uranium. New York, N.Y., Pergamon Press. 1967.

5. Callow, R. J. The rare earth industry. New York, N.Y., Pergamon Press. 1966.

6. Casto, M. G. The separation of lanthanum from a rare earth chloride mixture using a multistage mixersettler extractor. Unpublished M.S. thesis. Ames, Iowa, Library, Iowa State University. 1970.

7. Castro (sic) M. G., Smutz, M. and Bautista, R. G. Separation of lanthanum from a rare earth chloride mixture using a multistage mixer-settler. Society of Mining Engineers, AIME Transactions 250: 42-45. 1971.

8. Cheng, S. I. Column design and dynamics evaluation for fractional extraction of metals. Proceedings of the International Solvent Extraction Conference 2: 1025-1036. 1971.

9. Distefano, D. P., Măy, F. P. and Huckaba, C. E. Transient response and feed-forward control of a distillation tower subject to a sequence of upsets. American Institute of Chemical Engineers Journal $13: 125-131.1967$.

10. Erskine; W. Predictive control of an extraction column. Unpublished Ph.D. dissertation. Ames, Iowa, Library, Iowa State University. 1968. 
11. Halligan, J. E. and Smutz, M. Prediction of the approach to steady state of a mixer-settler extractor. Separation Science 1: 173-190. 1966.

12. Haskins, D. E. and Sliepcevich, C. M. The invariance principle of control for chemical processes. Industrial and Engineering Chemistry Fundamentals 4: 241-248. 1965.

13. Hirschhorn, I. S. The rare earth metals-new applications. Chemical Technology 1: 314-318. 1971.

14. Ioannou, T. A., Bautista, R. G. and Smutz, M. Correlating multicomponent equilibrium data for the extraction of lanthanides with di-(2-ethylhexyl)-phosphoric acid as the solvent. Proceedings of the International Solvent Extraction Conference 2: 957-965. 1971.

15. Kippenhan, N. and Gschneider, K. A. Rare-earth metals in steels. (Rare-Earth Information Center, Iowa state University, Ames) U.S. Atomic Energy Commission Report IS-RIC-4. 1970.

16. Lapidus, L. Digital computation for chemical engineers. New York, N.Y., McGraw-Hill Book Company, Inc. 1962.

17. Lowe, J. T. Calculation of the transient behavior of solvent extraction processes. Industrial and Engineering Chemistry Process Design and Development 7 : 362-366. 1968 .

18. Lupfer, D. E. and Parsons, J. R. A predictive control system for distillation columns. Chemical Engineering Progress 58: 37-42. 1962 .

19. Lubyen (sic) W. L. Feedforward control of distillation columns. Chemical Engineering progress 61: 74-78. 1965.

20. Luyben, W. L. Nonlinear feedforward control of chemical reactors. American Institute of Chemical Engineers Journal 14:37-45. 1968.

21. Luyben, W. L. and Lamb, D. E. Feed-forward control of a fluidized catalytic reactor-regeneration system. Chemical Engineering Progress Symposium Series: Process Systems Engineering 55: 165-171. 1963. 
22. Mackullin, E. C. and Shinskey, F. G. Feedforward analog computer control of a superfractionator. Control Engineering 11: 69-74. 1964.

23. National Materials Advisory Board. Trends in the usage of rare earths. National Materials Advisory Board Report-266. 1970.

24. Pollock, G. G. and Johnson, A. I. The dynamics of extraction processes: Part $I$. Introduction and critical review of ${ }^{\prime \prime}$ previous work. The Canadian Journal of Chemical Engineering 47: 469-476. 1969.

25. Rahn, R. W. and Smutz, M. Development of a laboratory scale continuous multistage extractor. Industrial and Engineering Chemistry Process Design and Development $8: 289-293$ : 1969:.

26. Souhrada, F., Landau, J. and Prochazka, I. Dynamic simulation of a stagewise mass transfer process with backmixing. The Canadian Journal of Chemical Engineering $48: 322-327$. 1970 .

27. Tinker, J. D. and Lamb, D. E. The design of a combined feedforward-feedback control system. Chemical Engineering Progress Symposium Series: Control and Applied Mathematics 55: 155-167. 1965.

28. U.S. Dept. of Interior. Bureau of Mines. The rareearth elements, yttrium, and thorium-a materials survey. U.S. Dept. of Interior Information Circular 8476. 1971 . 


\section{ACKNÓWLEDGMENTS}

The author wishes to express his appreciation to Dr. L. E. Burkhart for his guidance during the writing of this dissertation. Thanks are also due Mr. Tom Sandry for the hours of informal discussion. 